\title{
Eddy-covariance flux measurements with a weight-shift microlight aircraft
}

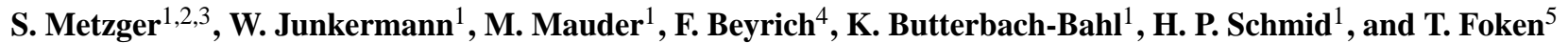 \\ ${ }^{1}$ Karlsruhe Institute of Technology, Institute for Meteorology and Climate Research, Atmospheric Environmental Research, \\ Garmisch-Partenkirchen, Germany \\ ${ }^{2}$ Chinese Academy of Sciences, Institute of Atmospheric Physics, State Key Laboratory of Atmospheric Boundary Layer \\ Physics and Atmospheric Chemistry, Beijing, China \\ ${ }^{3}$ National Ecological Observatory Network, Fundamental Instrument Unit, Boulder, USA \\ ${ }^{4}$ German Meteorological Service, Richard-Aßmann-Observatory, Lindenberg, Germany \\ ${ }^{5}$ University of Bayreuth, Department of Micrometeorology, Bayreuth, Germany
}

Correspondence to: W. Junkermann (wolfgang.junkermann@kit.edu)

Received: 18 February 2012 - Published in Atmos. Meas. Tech. Discuss.: 30 March 2012

Revised: 17 June 2012 - Accepted: 18 June 2012 - Published: 19 July 2012

\begin{abstract}
The objective of this study is to assess the feasibility and quality of eddy-covariance flux measurements from a weight-shift microlight aircraft (WSMA). Firstly, we investigate the precision of the wind measurement $\left(\sigma_{u, v} \leq 0.09 \mathrm{~m} \mathrm{~s}^{-1}, \sigma_{w}=0.04 \mathrm{~ms}^{-1}\right)$, the lynchpin of flux calculations from aircraft. From here, the smallest resolvable changes in friction velocity $\left(0.02 \mathrm{~m} \mathrm{~s}^{-1}\right)$, and sensible$\left(5 \mathrm{~W} \mathrm{~m}^{-2}\right)$ and latent $\left(3 \mathrm{~W} \mathrm{~m}^{-2}\right)$ heat flux are estimated. Secondly, a seven-day flight campaign was performed near Lindenberg (Germany). Here we compare measurements of wind, temperature, humidity and respective fluxes between a tall tower and the WSMA. The maximum likelihood functional relationship (MLFR) between tower and WSMA measurements considers the random error in the data, and shows very good agreement of the scalar averages. The MLFRs for standard deviations (SDs, 2-34\%) and fluxes (17-21\%) indicate higher estimates of the airborne measurements compared to the tower. Considering the $99.5 \%$ confidence intervals, the observed differences are not significant, with exception of the temperature SD. The comparison with a largeaperture scintillometer reveals lower sensible heat flux estimates at both tower $(-40$ to $-25 \%)$ and WSMA $(-25-$ $0 \%$ ). We relate the observed differences to (i) inconsistencies in the temperature and wind measurement at the tower and (ii) the measurement platforms' differing abilities to capture contributions from non-propagating eddies. These findings encourage the use of WSMA as a low cost and highly versatile flux measurement platform.
\end{abstract}

\section{Introduction}

Energy and matter fluxes between the Earth's surface and the atmosphere can be determined using the eddy-covariance (EC) method. This method is based on the Reynolds decomposition of the Navier-Stokes equation, and it assumes steady state conditions and horizontal homogeneity (e.g. Kaimal and Finnigan, 1994). Nevertheless, the EC method is frequently used in complex terrain, for which applicability is subject of on-going research (e.g. Foken et al., 2010; Göckede et al., 2008). In particular, it is assumed that the mean vertical wind approaches zero for a sufficiently long averaging interval. This requirement is more likely fulfilled by spatial than by temporal measurements, because spatial measurements enable registering atmospheric motions on larger scales (e.g. Mahrt, 2010). Under conditions of negligible advection and horizontal flux divergence, the total vertical flux is then inferred from the covariance between the vertical wind and the scalar of interest (e.g. temperature, humidity).

Ground-based measurements of turbulent fluxes are of local character and are therefore not necessarily representative of their greater surroundings, especially in complex terrain (e.g. Desjardins et al., 1997; Isaac et al., 2004b; Mahrt, 2010). The spatial gap between in-situ observations, satellite observations and modelled data needs to be considered as one plausible explanation for their frequently observed mismatch (e.g. Kanda et al., 2004; Lu et al., 2005). Here 
process studies with airborne platforms provide a valuable link to understand and bridge scale discrepancies (e.g. Bange et al., 2002; Davis et al., 1992; Hiyama et al., 2007; Isaac et al., 2004a). At the same time, fixed-wing aircraft and helicopters are expensive to operate or not applicable in settings such as remote areas beyond the range of an airfield. Unmanned aerial vehicles on the other hand provide mobility, yet do not allow a comprehensive sensor package due to payload restrictions (e.g. Egger et al., 2002; Hobbs et al., 2002; Martin et al., 2011; Thomas et al., 2012). Here the weightshift microlight aircraft (WSMA) can provide an alternative at low cost-, transport- and infrastructural demand. After successfully applying a WSMA to aerosol and radiation transfer studies (Junkermann, 2001, 2005), Metzger et al. (2011) showed that carefully computed wind measurements from WSMA are not inferior to those from other airborne platforms. On this basis, the feasibility of EC flux measurements from WSMA in the atmospheric boundary layer (ABL) is explored in this study. The overarching perspective is to work towards an airborne platform that allows characterising complex terrain in remote areas, including the measurement of regional turbulent fluxes.

Contributions to the EC flux measurement originate from turbulent atmospheric motions on a variety of wavelengths and amplitudes. In order to reliably estimate the total flux, the fluctuations of the vertical wind and the scalars must be measured with high accuracy and precision. Furthermore, the instrumentation and data acquisition must possess a suitable frequency response and sampling rate. In the case of airborne measurements, the carrier can additionally influence the spectral quality of the measurement. Therefore, the present study commences with (i) an assessment of the measurement errors. To evaluate the system performance, we (ii) compare spectral properties, averages, deviations and fluxes between WSMA and tower-based EC measurements. The analysis continues with (iii) a study of the measurements' spatial context, which is inferred from footprint modelling. The (iv) comparison to a large-aperture scintillometer (LAS) brings to attention the effect of larger-scale atmospheric motions on the results and completes the study.

\section{Materials and methods}

\subsection{The weight-shift microlight aircraft}

The structure of a WSMA differs from common fixed-wing aircraft: it consists of two distinct parts, the wing and the trike, which hangs below the wing and contains the pilot, engine and the majority of the scientific equipment. This particular structure provides the WSMA with exceptional transportability and climb rate, which qualifies it for applications in complex and inaccessible terrain. A detailed description of the physical properties of the WSMA used in this study as well as characteristics and manufacturers of sensors and data acquisition is given in Metzger et al. (2011). In short, most variables are sampled at $100 \mathrm{~Hz}$ and are block-averaged and stored at $10 \mathrm{~Hz}$, yielding a horizontal resolution of approximately $2.5 \mathrm{~m}$. To conduct fast wind measurements, the WSMA is outfitted with a combination of global positioning system and inertial measurement unit (GPS/IMU), and a five-hole pressure probe (5HP). The principle is to resolve the meteorological wind vector from the vector difference of the aircraft's inertial velocity (captured by the GPS/IMU) and the wind vector relative to the aircraft (captured by the 5HP). The structural features of the WSMA also influence the wind measurement: (i) the wing deforms aeroelastically with aircraft trim, and (ii) the trike is free to rotate in pitch and roll against the wing. Metzger et al. (2011) present a time domain procedure which treats the impact of the WSMA's structural features as well as pilot input on the wind measurement. The remaining maximum deviation of the vertical wind component is $0.15 \mathrm{~m} \mathrm{~s}^{-1}$ during severe vertical manoeuvres. At typical airspeeds between $23-30 \mathrm{~m} \mathrm{~s}^{-1}$, simultaneous wind measurements from WSMA and ground-based instrumentation agree within $0.3 \mathrm{~m} \mathrm{~s}^{-1}$ for the vertical and within $0.4 \mathrm{~m} \mathrm{~s}^{-1}$ for the horizontal components (root mean square error). The present study investigates the potential influence of resonance from the WSMA's engine or propeller, or from the natural frequencies of trike and wing, on the wind measurement. For this purpose, acceleration measurements in the hang point of trike and wing, in the global positioning system/inertial measurement unit and in the five-hole probe, are used. The acceleration measurement in the hang point is transformed to the trike coordinate system. A $100 \mathrm{~Hz}$ dataset consisting of $\approx 3 \times 10^{5}$ data points sampled during a level long-distance flight on 31 July 2009 (Metzger et al., 2011, Table 3) is used for the assessment.

Air temperature is measured with a $50 \mu \mathrm{m}$ thermocouple. The temperature error introduced by intermittent solar radiation at the unshielded thermocouple is $<0.05 \mathrm{~K}$ at nominal true airspeed (Metzger et al., 2011). An OP2 infrared gas analyser (IRGA, ADC Bioscientific, Great Amwell, UK) is used to measure the concentration of water vapour. The instrument response of both the thermocouple and the IRGA is $50 \mathrm{~Hz}$. In addition, a slow ( $2 \mathrm{~Hz}$ instrument response) humidity reference from a TP3 dew point mirror (Meteolabor AG, Wetzikon, Switzerland) is stored at $\geq 0.1 \mathrm{~Hz}$. Vertical profile flights revealed a dependence of the IRGA measurements on flight altitude. This dependence was related to a malfunctioning temperature compensation of the light source as well as air permeability of the light chamber. From measurements of calibration gases in a climate chamber, the temperature compensation is updated in post-processing. Similar measurements were conducted in a pressure chamber to determine the time constant of the light chamber permeability $(\approx 60 \mathrm{~s}$ or $1500 \mathrm{~m}$ of horizontal flight). In order to correct the permeability effect, a third-order Savitzky-Golay complementary filter (Chen et al., 2004) is used. The complementary filter corrects for the IRGA's drift by basing the humidity 
fluctuations measured by the IRGA on the slow dew point mirror reference. A window size of $13.9 \mathrm{~s}$ or $\approx 350 \mathrm{~m}$ maximises the integral over the humidity power spectrum, and is used to correct the measurements.

In the present study, also the influence of measurement precision on the eddy-covariance flux results is investigated. For this purpose, we follow Garman et al. (2006) and define measurement precision as $1 \sigma$ repeatability. The precision of all variables entering the EC flux calculation is presented in Table 1 . In the case of the GPS/IMU, precision originates from Kalman filter outputs, and in the case of the 5HP, it is calculated from laboratory and wind tunnel measurements (Metzger et al., 2011).

\subsection{Field campaign}

A comparison between the airborne WSMA and groundbased measurements was carried out during a flight campaign between 14 and 21 October 2008. This experiment was performed around the boundary layer field site Falkenberg $\left(52.2^{\circ} \mathrm{N}, 14.1^{\circ} \mathrm{E}\right)$ of the German Meteorological Service (DWD), Richard-Aßmann Observatory, Lindenberg, Germany. This field site lies in the basically flat North German Plain, and the terrain height varies between $40 \mathrm{~m}$ and $130 \mathrm{~m}$ above sea level (a.s.l.) within an area of $20 \times 20 \mathrm{~km}^{2}$. To characterize surface heterogeneity, we use the Corine Land Cover 2006 data with a horizontal resolution of $100 \mathrm{~m}$ (Version 13, European Environment Agency, 2010). The arable land was harvested before the study period, and, consequently, the surface properties differed mainly between but not within landscape units. We thus regrouped the 28 Corine Land Cover fractions in the study area into five landscape units, thereby reducing unnecessary scatter (Figs. 7 and 9). The resulting representation of the landscape around the Falkenberg site $\left(20 \times 20 \mathrm{~km}^{2}\right)$ is dominated by agriculture $(47 \%)$ and forests $(38 \%)$, interspersed by equal amounts $(5 \%)$ of lakes, meadows and settlements.

A full characterisation of the Falkenberg site and its instrumentation is presented by Beyrich and Adam (2007). Data from an instrumented $99 \mathrm{~m}$ tower are used for the comparison of the WSMA measurements. Sonic anemometers (USA-1 - Metek GmbH, Elmshorn, Germany) as well as open path IRGAs (LI-7500 - LI-COR Biosciences, Lincoln, USA) were installed at $50 \mathrm{~m}$ and $90 \mathrm{~m}$ above ground level (a.g.l.). These instruments sampled the wind vector, sonic temperature and humidity at a rate of $20 \mathrm{~Hz}$, enabling EC flux computation. For the USA-1, the manufacturer's 2-D flow distortion correction was operationally applied to the wind vector measurement. These data are used for the comparison of the average wind as well as variances, covariances and power spectra between the WSMA and the tower. The tower was further equipped with profile measurements of temperature (HMP-45 - Vaisala Oy, Helsinki, Finland) and humidity (Frankenberger Psychrometer - Theodor Friedrichs GmbH, Hamburg, Germany) at 40, 60, 80, and $98 \mathrm{~m}$ a.g.l.
Table 1. Measurement precision of global positioning system/inertial measurement unit (GPS/IMU), five-hole probe (5HP), thermocouple, and infrared gas analyzer (IRGA).

\begin{tabular}{ll}
\hline Quantity & Precision \\
\hline Heading (GPS/IMU) & $0.1^{\circ}$ \\
Pitch, Roll (GPS/IMU) & $0.04^{\circ}$ \\
3-D velocity (GPS/IMU) & $0.02 \mathrm{~m} \mathrm{~s}^{-1}$ \\
3-D angular rate (GPS/IMU) & $0.01^{\circ} \mathrm{s}^{-1}$ \\
3-D acceleration (GPS/IMU) & $0.01 \mathrm{~m} \mathrm{~s}^{-2}$ \\
Attack angle (5HP) & $0.08^{\circ}$ \\
Sideslip angle (5HP) & $0.18^{\circ}$ \\
True airspeed (5HP) & $0.05 \mathrm{~m} \mathrm{~s}^{-1}$ \\
Temperature (thermocouple) & $0.04 \mathrm{~K}^{-3}$ \\
Humidity (IRGA) & $0.005 \mathrm{~g} \mathrm{~m}^{-3}$ \\
\hline
\end{tabular}

The profiles are interpolated to the heights of the EC installations and are used to compare average temperature and humidity between tower and WSMA. A static pressure measurement (PTB220A - Vaisala Oy, Helsinki, Finland) at $74 \mathrm{~m}$ a.s.l. is extrapolated to the heights of the tower EC installations using the hypsometric equation. It is used for the conversion of the tower EC fluxes from kinematic units to units of energy. Tower profile and pressure data were averaged and stored in $10 \mathrm{~min}$ intervals.

Identical instrumentation as on the tower was used for an additional EC surface flux measurement upwind (south) of the tower base, at $2.4 \mathrm{ma.g} .1$. The half-hourly sensible heat flux was determined from this measurement as an operational product of the DWD. Global radiation was measured at $2 \mathrm{~m}$ using a CM24 pyranometer/albedometer (Kipp and Zonen, Delft, The Netherlands) and stored as $10 \mathrm{~min}$ averages. Also $10 \mathrm{~min}$ area-averaged surface sensible heat fluxes were derived from a large-aperture scintillometer. At an effective beam height of $43 \mathrm{~m}$ a.g.l., the near-infrared LAS runs along a path length of $4.7 \mathrm{~km}$ (Fig. 9). The LAS was developed and built by the Meteorology and Air Quality Group of the Wageningen University; technical details are presented in Meijninger et al. (2006). Furthermore, hourly estimates of the ABL depth were derived from sonic detection and ranging and wind profiler data, and from six-hourly routine radio soundings performed by the DWD. The surface sensible heat fluxes measured at the $2.4 \mathrm{~m}$ EC and the LAS are used in conjunction with the ABL depths to approximate vertical flux profiles. Simultaneous WSMA measurements of the sensible heat flux are compared to these flux profiles.

In the course of the flight campaign, the atmospheric conditions changed from very weak to strong turbulent mixing. The cloud cover (09:00 to 15:00 UTC) decreased from 8/8 to $4 / 8$, and the maximum available global radiation increased from $280 \mathrm{~W} \mathrm{~m}^{-2}$ at the beginning to $460 \mathrm{~W} \mathrm{~m}^{-2}$ at the end of the campaign. Also the wind speed increased from $2 \mathrm{~m} \mathrm{~s}^{-1}$ to $10 \mathrm{~m} \mathrm{~s}^{-1}$ at the $50 \mathrm{~m}$ tower level, with the wind direction 
changing from west to south. The ranges of the surface sensible and the latent heat fluxes were $0-100 \mathrm{~W} \mathrm{~m}^{-2}$ and $0-200 \mathrm{~W} \mathrm{~m}^{-2}$, respectively. The sensible heat flux slightly increased in the course of the campaign, while the latent heat flux remained approximately comparable throughout the flight days. Also the maximum ABL depth increased from $250 \mathrm{~m}$ to $1150 \mathrm{~m}$ in the course of the campaign. The atmospheric stratification was neutral to unstable, with the median of the stability parameter $z / L=-0.18 \pm 0.21$ from WSMA and $-0.14 \pm 0.29$ from tower measurements.

\subsection{Data processing}

Eddy-covariance data were post-processed analogously for the $99 \mathrm{~m}$ tower and for the WSMA turbulence measurements. The software package TK3 (Mauder and Foken, 2011) was used to process the tower EC data, applying the raw data treatments and flux corrections as put forward in Foken et al. (2012). (i) The raw data were screened for spikes using the algorithm of Hojstrup (1993). Visual inspection revealed that neighbouring spikes in the IRGA data were not detected by the algorithm. The original algorithm uses average and standard deviation criteria with low break down points for small sample sizes (Rousseeuw and Verboven, 2002). After substituting the criteria with the median and the median absolute deviation, the spikes were efficiently removed. (ii) The time delay due to separation between the vertical wind measurement and adjacent sensors was determined and corrected by maximizing their lagged correlation. (iii) To correct for potential misalignment, the USA-1 wind measurement was rotated into the streamline coordinate system using the planar-fit method by Wilczak et al. (2001). (iv) The temperature variance as well as the sensible heat flux was calculated using the crosswind correction by Liu et al. (2001). (v) The formulations by Webb et al. (1980) were used to correct the latent heat flux for density fluctuations.

To handle the WSMA data, an analysis package with similar processing steps was developed in GNU R version 2.13 (R Development Core Team, 2011), which is available upon request. Several forenamed corrections are not applicable to the WSMA measurement and were omitted: (iii) the aircraft vertical wind is already defined in geodetic normal, which is perpendicular to the spatial average of the streamlines, and (iv) the air temperature is directly measured by the thermocouple. The sensitivity of the WSMA measured fluxes on the remaining corrections was tested for a flight in the convective boundary layer $(z / L=-0.8)$ at $50 \mathrm{~m}$ a.g.l. No spikes were present in this dataset, and consequently the spike elimination (i) had no influence on the results. The corrections for time delay (ii), high frequency spectral loss (Moore, 1986) and density fluctuations (v) only affected the latent heat flux. The median differences between applying and neglecting these corrections were in the order of $5 \%, 1 \%$ and $20 \%$, respectively, which is in agreement with the findings of Mauder and Foken (2006). In the following, the correction for high frequency loss due to sensor separation is not applied because its influence is negligible at measuring heights $\geq 50 \mathrm{~m}$. The fluxes computed from both software packages were compared using regression analysis and showed perfect agreement with unity slope. Consequently, comparability is ensured when calculating fluxes from tower and WSMA platforms with their respective software packages.

\subsection{Evaluation strategy}

\subsubsection{Propagation of sensor errors}

The eddy-covariance technique relies upon the precise measurement of fluctuations of atmospheric quantities, based on negligible sensor drift throughout an averaging period. Our intention is to evaluate whether sensor precision and drift facilitate the use of the weight-shift microlight aircraft as turbulence measurement platform. Measured from aircraft, the determination of the wind vector requires a sequence of thermodynamic and trigonometric equations (e.g. Metzger et al., 2011). These equations propagate various sources of error, and are consequently the lynchpin for EC flux measurements from aircraft. Here we propagate known sensor precisions to atmospheric quantities, which yields the minimum resolvable change in the associated fluxes. Thereafter, the maximum achievable averaging period for the flux calculation is determined as a function of sensor drift.

\subsubsection{Spectral properties of the aircraft}

As opposed to ground-based measurements, the weight-shift microlight aircraft is subject to several simultaneous motions, such as locomotion, engine and propeller rotation. Our intention is to assess if and to what extent the WSMA's motions influence the wind measurement. For this purpose, a spectral analysis was carried out by fast Fourier transformation of acceleration measurements in the hang point of trike and wing, in the global positioning system/inertial measurement unit and in the five-hole probe. We present power spectra representative for these structural parts of the WSMA and interpret the spectral behaviour in the context of the wind measurement.

\subsubsection{Comparison between tower and aircraft measurements}

Measurements with the weight-shift microlight aircraft were conducted along a cross-shaped pattern within $1.5 \mathrm{~km}$ horizontal distance of the tall tower from 15 to 18 October 2008 (Fig. 7). A total of 36 flights of $3 \mathrm{~km}$ length or $\approx 120 \mathrm{~s}$ duration are compared to simultaneous tower measurements. The WSMA was travelling at two different airspeeds, $24 \mathrm{~m} \mathrm{~s}^{-1}$ and $27 \mathrm{~m} \mathrm{~s}^{-1}$, and was flying within $0.5 \pm 5.3 \mathrm{~m}$ altitude of the corresponding installations on the tower. The WSMA temperature and densities were transformed to potential quantities at the respective tower height. The objective of the 
comparison is to assess the quality of the WSMA measurement, with focus on the EC flux. The objective is not to quantify the actual exchange between surface and atmosphere. The comparatively short flight legs are therefore a compromise of sample size $(\approx 1200$ data points from WSMA) and vicinity of the measurement platforms.

Differing spectral contributions can lead to a systematic bias in the flux estimates between the platforms. To ensure equal contributions from the long wave part of the spectrum, we constrain the averaging periods to the same normalized frequency. The tower averaging period $\tau_{\text {tow }}=\tau_{\text {air }} \cdot v_{\text {tas }} /|\boldsymbol{u} \boldsymbol{v} \boldsymbol{w}|$ then results from the flight duration for one leg $\tau_{\text {air }}$ and the ratio of airspeed $v_{\text {tas }}$ to the module of the wind vector $|\boldsymbol{u} \boldsymbol{v} \boldsymbol{w}|$. For $\tau_{\text {air }} \approx 120 \mathrm{~s}$ and the ratio $v_{\text {tas }} /|\boldsymbol{u} \boldsymbol{v} \boldsymbol{w}| \approx 5$, the appropriate tower averaging period is $\tau_{\text {tow }} \approx 600 \mathrm{~s}$ or $10 \mathrm{~min}$. Using this averaging period, the tower results were calculated at increments of $1 \mathrm{~min}$. The WSMA was more frequently travelling upwind ( $180 \pm 720 \mathrm{~m}$ median difference) than downwind of the tower. In a window of \pm 10 increments, the tower result was chosen that minimized the scatter (root mean square error) between all flux measurements of both platforms. This allows taking into account advection between the platforms, as well as potential timing differences of the data acquisition systems. Best agreement was reached for a shift of $2 \pm 6$ increments, corresponding to an upwind distance of $600 \pm 1800 \mathrm{~m}$ for an air mass travelling at $5 \mathrm{~m} \mathrm{~s}^{-1}$.

In order to detect systematic differences between tower and WSMA measurements, a regression-like analysis was applied to all 36 flights. Simple least-squares regression is strictly applicable only when one measurement is without error (Lindley, 1947). This however is not the case for the measurements in our study, which are subject to uncertainties such as random statistical error. Instead, we use maximumlikelihood fitting of a functional relationship (MLFR, Ripley and Thompson, 1987). This method assigns a weight to each data couple in the relationship, which is inversely proportional to its error variances. In our case, the squared random statistical errors in the tower and WSMA measurements are used, which appreciates reliable data and depreciates uncertain data couples. These errors are inferred from the integral length scales of the WSMA measurements (Appendix A), and define an inner and an outer scale of confidence in the comparison. The errors in the MLFR coefficients are determined from a jackknife estimator (Quenouille, 1956; Tukey, 1958). Since the regression intercepts were not significant, the relationships were forced through the origin, and confidence intervals were determined from the slope error. The coefficient of determination $R^{2}$ was calculated in analogy to weighted least-squares regression (Kvalseth, 1985; Willett and Singer, 1988). It is the proportion of variation in weighted $Y$ that can be accounted for by weighted $X$. Finally, the residual standard error is determined using Eq. (A4).

\subsubsection{Spatial analysis}

We use footprint modelling in order to assess the spatial context of measurements. For this purpose, the along-wind footprint parameterization of Kljun et al. (2004) was combined with a suitable crosswind distribution (Appendix B). The resulting model is computationally fast, considers 3-D dispersion and is applicable beyond the atmospheric surface layer. We compare the overlap of the tower and WSMA footprints as well as the contribution of different land covers to the measurements.

\subsubsection{Comparison with large-aperture scintillometer}

In addition to tower- and aircraft-based eddy-covariance measurements, we also include sensible heat flux estimates from the large-aperture scintillometer in the comparison. On seasonal average, LAS measures 10-20\% higher values of the sensible heat flux compared to tower EC measurements (e.g. Liu et al., 2011; Meijninger et al., 2006). In particular above heterogeneous terrain, the capture of elevated, nonpropagating eddies (NPE) by the LAS, but not by the tower $\mathrm{EC}$, is discussed as a potential reason for the observed differences (Foken et al., 2010). In this respect, the spatially averaged EC measurement from WSMA is similar to the LAS. Consequently, the objective of the comparison with LAS is to aid the interpretation of systematic differences between the spatially (aircraft) and temporally (tower) averaged EC measurements. On 20 and 21 October 2008, two flights of $4.7 \mathrm{~km}$ length or $\approx 150 \mathrm{~s}$ duration were conducted $\approx 1 \mathrm{~km}$ to the east of, and parallel to the LAS measuring path (Fig. 9). The duration of the WSMA flight translates to $\approx 750 \mathrm{~s}$ or $12.5 \mathrm{~min}$ averaging interval at the $50 \mathrm{~m}$ and $90 \mathrm{~m}$ levels of the tower. Nevertheless, the tower flux measurements are averaged over $10 \mathrm{~min}$, identical to Sect. 2.4.3. For longer averaging intervals, the time series became increasingly instationary on 21 October 2008, and the flux magnitude decreased. WSMA temperature and density measurements were transformed to potential quantities at the mean flight altitude, i.e. $108 \mathrm{~m}$ and $119 \mathrm{~m}$ a.g.l. on 20 and 21 October 2008, respectively. Using boundary layer scaling, the results from LAS and WSMA are compared to simultaneous tower EC measurements at $2.4 \mathrm{~m}, 50 \mathrm{~m}$ and $90 \mathrm{~m}$ a.g.l., which are located at the LAS transmitter site.

\section{Results}

\subsection{Propagation of sensor errors}

In the first part of this section, we assess the WSMA's measurement precision and its impact on EC flux measurements over short flight legs. In the second part, we evaluate the maximum flux averaging period facilitated by the drift (accuracy) of the sensors. 


\subsubsection{Measurement precision and least resolvable flux}

The measurement precisions in Table 1 were superimposed over the turbulence raw data of the 36 tower-aircraft comparison flights $(N=37000)$. Both original and manipulated datasets were processed through the entire wind computation, and the deviations in the wind components were compared $\left(\sigma_{u}=0.07 \mathrm{~m} \mathrm{~s}^{-1}, \sigma_{v}=0.09 \mathrm{~m} \mathrm{~s}^{-1}, \sigma_{w}=0.04 \mathrm{~m} \mathrm{~s}^{-1}\right)$. Drawing on Lenschow and Sun (2007), we assume that a minimum signal-to-noise ratio of $5: 1$ is required to measure the wind fluctuations with sufficient precision for EC applications. Thus, standard deviations of $\leq 0.45 \mathrm{~m} \mathrm{~s}^{-1}$ and $0.20 \mathrm{~m} \mathrm{~s}^{-1}$ are reliably resolved in the horizontal and vertical wind components, respectively. For all 36 flights, the original and manipulated datasets were further propagated through the EC algorithm, also considering the precisions of the fast temperature and humidity measurement (Table 1). The result is an estimate of the least resolvable change in the measured flux $\left(\sigma_{u^{*}}=0.003 \mathrm{~m} \mathrm{~s}^{-1}, \sigma_{H}=0.9 \mathrm{~W} \mathrm{~m}^{-2}\right.$, and $\sigma_{E}=0.5 \mathrm{~W} \mathrm{~m}^{-2}$ ). Using the above signal-to noise-ratio of $5: 1$, changes in friction velocity, sensible- and latent heat of $0.02 \mathrm{~m} \mathrm{~s}^{-1}, 5 \mathrm{~W} \mathrm{~m}^{-2}$, and $3 \mathrm{~W} \mathrm{~m}^{-2}$, respectively, are reliably resolved.

\subsubsection{Measurement accuracy and maximum averaging interval}

The above repeatability does not consider the environmental changes (temperature, humidity, pressure ...) which are experienced by the sensors measuring aboard a moving aircraft. Changes in the environment likely lead to sensor drift, increasingly deteriorating the measurement with flight duration. In the following, we assess whether the measurement accuracy warrants the resolution of horizontal ABL structures up to the mesoscale $(10-100 \mathrm{~km})$. We start with the vertical wind measurement, because its signal levels and largescale variability are low compared to the horizontal wind components or the scalars. We use the methods of Lenschow and Sun (2007), and first estimate the required signal level:

$$
\frac{\partial w}{\partial t}<0.2 \sqrt{2} \sigma_{w} 2 \pi k v_{\text {tas }}=1.4 \times 10^{-4} \mathrm{~m} \mathrm{~s}^{-2}
$$

from the mesoscale variability of the vertical wind $\sigma_{w}=$ $0.1 \mathrm{~m} \mathrm{~s}^{-1}$, corresponding wavenumber $k=2.8 \times 10^{-5} \mathrm{~m}^{-1}$, and true airspeed $v_{\text {tas }}=28 \mathrm{~m} \mathrm{~s}^{-1}$. The required signal level is compared to the accuracy of the vertical wind measurement, using Eq. (5) from Lenschow and Sun (2007):

$$
\frac{\partial w}{\partial t} \cong \Theta \frac{\partial v_{\text {tas }}}{\partial t}+v_{\text {tas }} \frac{\partial \Theta}{\partial t}+v_{\text {tas }} \frac{\partial w_{\text {AIR }}}{\partial t}=1.1 \times 10^{-4} \mathrm{~m} \mathrm{~s}^{-2},
$$

\section{II III}

with $\Theta=\alpha-\theta$, the (radians) angles of attack $\alpha$, and pitch $\theta$, and the aircraft vertical velocity $w_{\text {AIR }}$. Here we apply the combined accuracies of the sensors and the wind model description, $\partial v_{\text {tas }}=0.34 \mathrm{~m} \mathrm{~s}^{-1}, \partial \Theta=1.1 \times 10^{-2}$, and $\partial w_{\text {AIR }}=0.02 \mathrm{~m} \mathrm{~s}^{-1}$ (Metzger et al., 2011) over $\partial t=1 \mathrm{~h}$ duration of a $100 \mathrm{~km}$ flight leg. With $\Theta$ rarely exceeding \pm 0.17 radians, terms I, II and III in Eq. (2) equate to $1.7 \times 10^{-5} \mathrm{~m} \mathrm{~s}^{-2}, 8.4 \times 10^{-5} \mathrm{~m} \mathrm{~s}^{-2}$, and $0.6 \times 10^{-5} \mathrm{~m} \mathrm{~s}^{-2}$, respectively. It can be seen that the overall performance is limited by the accuracy of $\Theta$ in the second term. This accuracy is dominated by the dynamic and differential pressure measurements used to infer $\alpha$.

Analogously, the signal level required for the horizontal wind components $\left(1.8 \times 10^{-3} \mathrm{~m} \mathrm{~s}^{-2}\right)$ and their measurement accuracy $\left(\leq 1.9 \times 10^{-4} \mathrm{~m} \mathrm{~s}^{-2}\right)$ are calculated (Lenschow and Sun, 2007). Again, the dynamic and differential pressure measurements used to infer true airspeed and sideslip angle are the weakest link.

Accuracy in the scalar measurements along a flight leg is constrained by the drifts of the fast thermocouple $(7.2 \times$ $\left.10^{-5} \mathrm{~K} \mathrm{~s}^{-1}\right)$ and the dew point mirror $\left(2.8 \mathrm{ppm} \mathrm{s}^{-1}\right)$. Using the same 1:5 signal-to-noise criteria as in Eq. (1), temperature- and humidity fields differing $>1.3 \mathrm{~K}$ or $>5 \%$ mixing ratio, respectively, can be reliably distinguished throughout a $100 \mathrm{~km}$ flight leg.

\subsection{Spectral properties of the aircraft}

Various motions of the weight-shift microlight aircraft can potentially disturb the wind measurement. For comparison with the wind power spectra, we assess potential resonance from the engine or propeller of the WSMA, as well as the natural frequencies of trike and wing. Transverse and especially vertical to the WSMA body, accelerations of the fivehole probe agree well with measurements from the global positioning system/inertial measurement unit up to a frequency of $2-3 \mathrm{~Hz}$ (Fig. 1). At higher frequencies, the acceleration measurements at the 5HP continue to follow the pattern of GPS/IMU accelerations, though are slightly enhanced. This is expected, since the 5HP has a longer lever $(\approx 0.5 \mathrm{~m})$ with respect to the centre of rotation, i.e. the hang point of wing and trike. Consequently, the acceleration amplitudes are higher at the 5HP, which is accounted for in the lever arm correction of the wind measurement. The spectral peaks at 30 and $45 \mathrm{~Hz}$ are likely to be associated with harmonics from the engine and propeller, rotating at $\approx 100 \mathrm{~Hz}$ and $\approx 30 \mathrm{~Hz}$, respectively. Because the $-3 \mathrm{~dB}$ point $(20 \mathrm{~Hz})$ of the 5HP's low-pass filter is lower than the data acquisition's Nyquist frequency $(50 \mathrm{~Hz})$, aliasing of the wind measurement is however not a problem. For the acceleration component longitudinal to the WSMA, the 5HP pattern is enhanced compared to the GPS/IMU. This is surprising, since it is the axis of plug- and socket connection between GPS/IMU and 5HP, i.e. the axis with the least margin for resonance. We speculate that the reason for the observed difference lies in the fixture of the acceleration sensor in the 5HP, rather than in the mounting of the 5HP against the GPS/IMU. This could also partially explain the slightly enhanced energy in the 5HP transverse and vertical acceleration spectra. The spectral 
behaviour of the wing acceleration measurements is different to those of the trike. It displays a distinct peak around $0.7 \mathrm{~Hz}$, which is only present in the transverse component of the trike measurements. It can be understood as the wing's natural frequency, i.e. its inertia. In Sect. 3.3 the spectral characteristics of the wind measurement are related to these properties.

\subsection{Comparison between tower and aircraft measurements}

Here we compare average quantities, standard deviations (SD) as well as turbulent fluxes between tower and weightshift microlight aircraft measurements. The objective is to reveal systematic differences between the platforms and identify their causes, such as instrument- or platform-related problems.

\subsubsection{Statistical error}

To unveil systematic differences between the platforms, we have to take into account the random statistical error of the measurements (Sect. 2.4.3). For this purpose, the integral length scales of scalars and fluxes were computed from WSMA measurements using Eq. (A1). The length scales for each flight were then used to calculate the average- and the ensemble random errors $\sigma_{\text {ran }}$ and $\sigma_{\text {ens }}$, respectively, using Eqs. (A2)-(A5). In Table 2, the errors are summarized for each variable in the comparison between tower and WSMA. The average random errors are low for the measurement of averages $(<1-15 \%)$ and standard deviations (5-9\%), and higher for the friction velocity and the heat fluxes (25-34\%). Likewise, $\sigma_{\text {ens }}$ increases from averages and SDs to fluxes. The comparison of the entire dataset between tower and WSMA is associated with an overall uncertainty of $\leq 3 \%$ for the averages, $\leq 2 \%$ for SDs and $\leq 8 \%$ for the fluxes. In the following sections, these errors are used to derive the maximum likelihood functional relationships between tower and WSMA measurements.

\subsubsection{Averages}

The averages of vertical and along-wind components, temperature and absolute humidity were compared between tower and airborne measurements. The vertical wind measurements agree within several centimetres and show similar variability (Fig. 2). Taking into account the natural scatter in the data, the average vertical wind is not significantly different from zero for both platforms. This confirms our assumption that the aircraft vertical wind (in geodetic normal) is perpendicular to the spatial average of the streamlines. For the along-wind component, temperature and humidity measurements, the maximum likelihood relationship between tower and WSMA was calculated (Fig. 2). The error bars correspond to the random statistical error in the measurements, and the weight of each point in the relationship is represented by the size of the circles. Also shown are the slope $f(x)$,
Table 2. Results of the maximum likelihood functional relationships between tower and WSMA measurements. Shown are the MLFR slope and its standard error Slope $\pm \sigma$, weighted coefficient of determination $R^{2}$, residual standard error $\sigma_{\text {res }}$, the average random statistical error $\sigma_{\text {ran }}$ and the ensemble random error $\sigma_{\text {ens. }}$.

\begin{tabular}{|c|c|c|c|c|c|}
\hline Variable & Slope $\pm \sigma$ & $R^{2}$ & $\sigma_{\text {res }}$ & $\sigma_{\text {ran }}$ & $\sigma_{\text {ens }}$ \\
\hline \multicolumn{6}{|l|}{ Averages } \\
\hline$u$ & $0.99 \pm 0.02$ & 1.00 & $9 \%$ & $15 \%$ & $3 \%$ \\
\hline$T$ & $1.00 \pm 0.00$ & 1.00 & $0 \%$ & $0 \%$ & $0 \%$ \\
\hline$a$ & $0.99 \pm 0.00$ & 1.00 & $1 \%$ & $2 \%$ & $0 \%$ \\
\hline \multicolumn{6}{|c|}{ Standard deviations } \\
\hline$u$ & $1.15 \pm 0.05$ & 0.99 & $21 \%$ & $9 \%$ & $2 \%$ \\
\hline$v$ & $1.02 \pm 0.05$ & 0.98 & $20 \%$ & $8 \%$ & $1 \%$ \\
\hline$w$ & $1.10 \pm 0.03$ & 0.99 & $9 \%$ & $5 \%$ & $1 \%$ \\
\hline$T$ & $1.34 \pm 0.07$ & 0.98 & $17 \%$ & $7 \%$ & $1 \%$ \\
\hline$a$ & $1.17 \pm 0.08$ & 0.98 & $23 \%$ & $9 \%$ & $1 \%$ \\
\hline \multicolumn{6}{|l|}{ Fluxes } \\
\hline$u_{*}$ & $1.21 \pm 0.07$ & 0.98 & $13 \%$ & $25 \%$ & $5 \%$ \\
\hline$H$ & $1.17 \pm 0.08$ & 0.98 & $10 \%$ & $29 \%$ & $8 \%$ \\
\hline$L E$ & $1.17 \pm 0.10$ & 0.96 & $25 \%$ & $34 \%$ & $7 \%$ \\
\hline
\end{tabular}

the residual standard error $\sigma_{\text {res }}$ and the weighted coefficient of determination $R^{2}$ of the MLFR. Along-wind, temperature and humidity measurements agree well between the two platforms. The slopes are not significantly different from unity, and the MLFR explains $\geq 99 \%$ of the variance in the dataset. In case of temperature and humidity, the $99.5 \%$ confidence intervals are actually too narrow to be distinguished from the MLFR line. In order to assess the integrity of the MLFR, the results can be compared to the average- and the ensemble random errors $\sigma_{\text {ran }}$ and $\sigma_{\text {ens }}$, respectively. The error in the residuals $\sigma_{\text {res }}$ measures the random scatter not accounted for by the MLFR, and should be lower than the average random error $\sigma_{\text {ran }}$. In the presented data, $\sigma_{\text {res }}$ is below $\sigma_{\text {ran }}$ (Table 2), indicating that the significance of the MLFR exceeds the average random error. Likewise, we expect more confidence in the MLFR slope when the ensemble random error $\sigma_{\mathrm{ens}}$ is small. Here the errors in the slopes and $\sigma_{\text {ens }}$ are equally small, emphasizing the close relationships.

\subsubsection{Spectra and standard deviations}

Before investigating covariances, the spectra and standard deviations of the individual variables are compared between the tower and WSMA measurements. In order to assess the spectral quality, the 36 tower and WSMA data series used for the MLFRs were transferred into frequency domain using fast Fourier transformation. Each individual transform was normalized to a sum of unity. To reduce scatter, the normalized transforms of all tower and WSMA measurements, respectively, were then binned into frequency bands and ensemble-averaged. Figure 3 shows the average power spectra of vertical and horizontal wind, temperature and humidity for the tower and WSMA measurements. The power spectra 

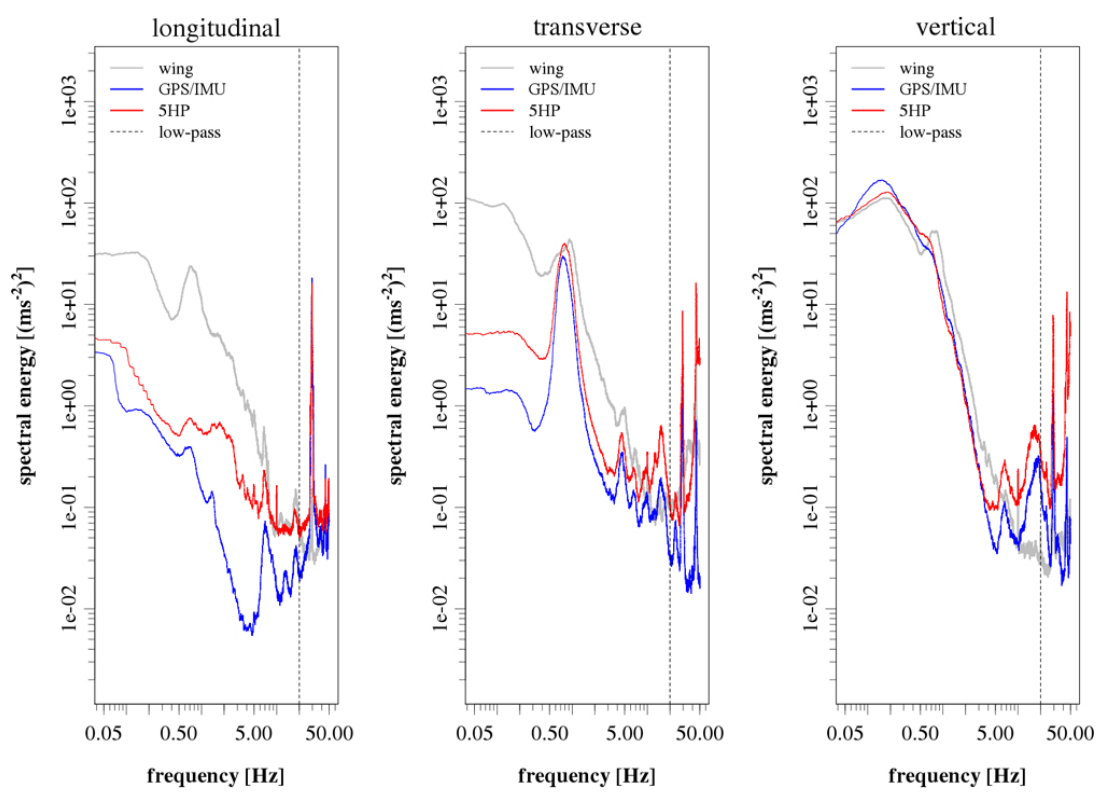

Fig. 1. Smoothed power spectra of acceleration measurements in the WSMA trike coordinate system. The dashed vertical line indicates the $-3 \mathrm{~dB}$ frequency $(20 \mathrm{~Hz})$ of the Butterworth low-pass filter in the wind vector data acquisition system.
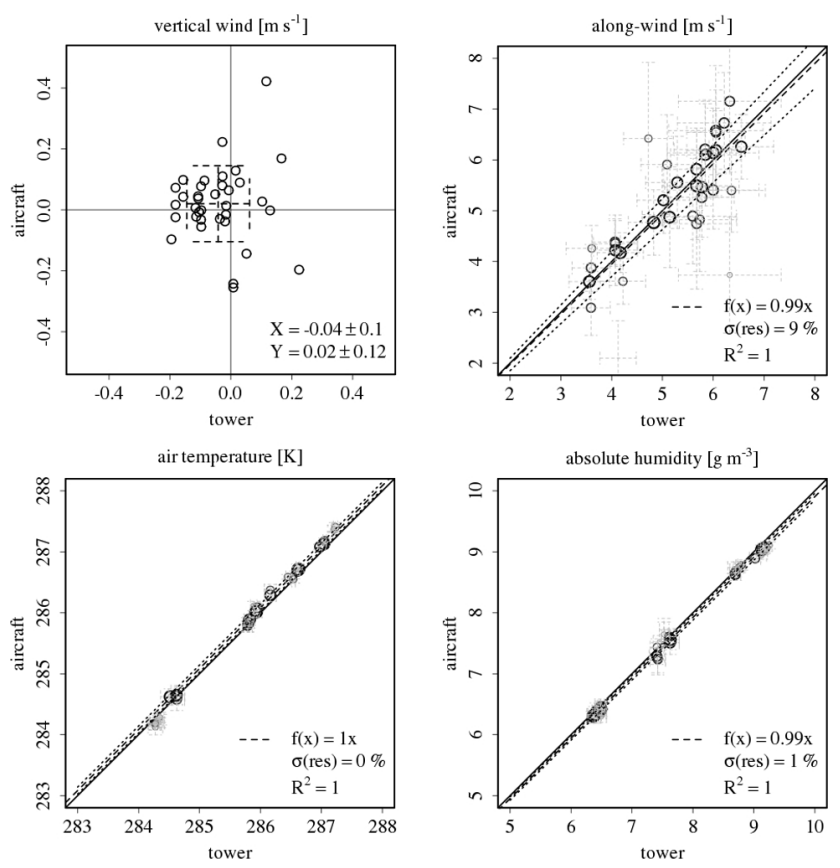

Fig. 2. Comparison between tower and WSMA averages of verticaland along-wind components, temperature and absolute humidity. Average and standard deviation are given for the vertical wind. For along-wind, temperature and humidity, the solid, dashed and dotted lines are the $1: 1$ line, the maximum likelihood functional relationship, and the $99.5 \%$ confidence interval, respectively. Additional information is given in the text. are presented as function of observation frequency to enable the association with the physical properties of the WSMA. Due to fewer samples per dataset, the scatter in the WSMA spectra is higher at low frequencies. We use the streamwise component of the horizontal wind, i.e. in the direction of the mean wind and in the direction of the mean aircraft heading for tower and WSMA, respectively. The sonic temperature spectrum at the tower is compared to the air temperature spectrum at the WSMA. Kolmogorov (1941) defined the $f^{-5 / 3}$ law of isotropic turbulence for the inertial sub-range of atmospheric turbulence $(\approx 0.05-5 \mathrm{~Hz})$. All variables, with exception of the WSMA vertical wind and the tower sonic temperature, follow the $f^{-5 / 3}$ law well (Fig. 3). The vertical wind and to a lesser degree also the streamwise wind component of the WSMA show a spectral peak between $0.4-2 \mathrm{~Hz}$, coinciding with the wing's natural frequency (Sects. 3.2 and 4). Compared to the $f^{-5 / 3}$ law and relative to the entire frequency range, the standard deviations in the wind components are overestimated by $8 \pm 3 \%$ and $2 \pm 1 \%$, respectively (median differences). In the WSMA transverse direction, the wind SD is overestimated by $5 \pm 4 \%$ at lower frequencies from $0.15-0.4 \mathrm{~Hz}$ (not shown). On the other hand, the power spectrum of the tower sonic temperature does not follow the $f^{-5 / 3}$ law very well. For frequencies above $0.3 \mathrm{~Hz}$, the SD is overestimated by $29 \pm 19 \%$. The pattern is consistent for both sonic anemometers at different measurement heights.

The SD of each individual measurement was corrected for spectral artifacts before case-by-case comparison between WSMA and tower. The MLFRs show that the WSMA measures $10 \%$ and $15 \%$ higher SDs in the vertical and along-wind components, respectively, compared to the tower 

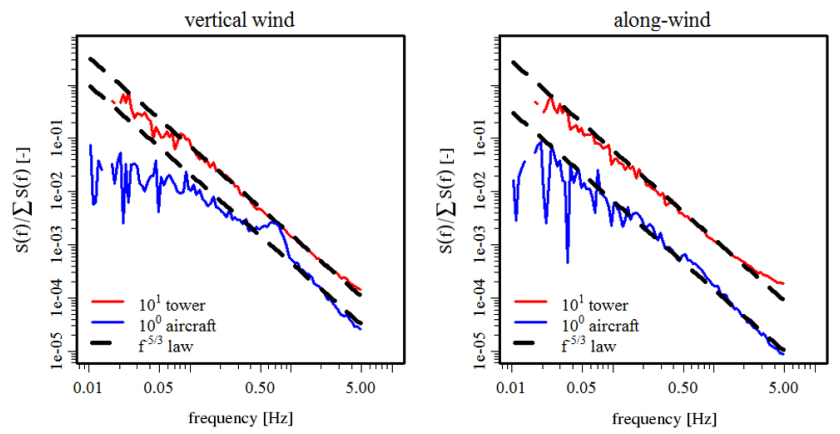

temperature
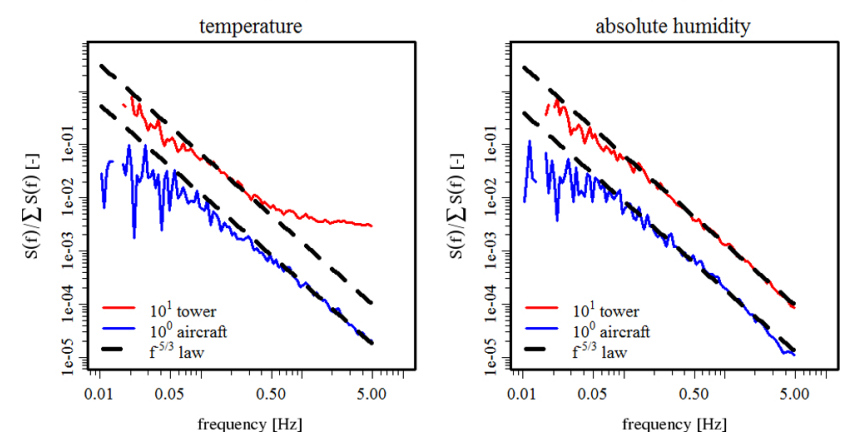

Fig. 3. Average power spectra of all measurements between tower and WSMA. To improve legibility, the tower data are offset by one order of magnitude. Also shown is the $f^{-5 / 3}$ law of isotropic turbulence (dashed line). Additional information is given in the text.

(Fig. 4). To a lesser degree, this behaviour is also found in the $\mathrm{SD}$ of the cross-wind component ( $2 \%$, not shown). Also for temperature $(34 \%)$ and humidity $(17 \%)$, the WSMA measures higher SDs compared to the tower. However, the difference is significant only for the temperature measurement, while the $99.5 \%$ confidence intervals for all other measurements approximately include unity slope. All MLFRs explain $\geq 98 \%$ of the variance in the data. The ensemble random errors are smaller than the slope errors, but the residual standard errors exceed their respective average random statistical error (Table 2). This can partially be attributed to very small denominators in the calculation of $\sigma_{\text {res }}$, but it is also a result of the natural scatter in the data. This indicates that $\sigma_{\text {ran }}$ and $\sigma_{\text {ens }}$ are potentially overoptimistic estimates of the spatial variability in the scalar fields.

\subsubsection{Cospectra and fluxes}

The correlation of horizontal and vertical wind components was compared between tower $(-0.31 \pm 0.14)$ and WSMA $(-0.33 \pm 0.13)$ measurements. Both values are close to one another and within the characteristic range from -0.15 to -0.35 (e.g. Foken et al., 2004). However, increased correlation due to spectral properties of the WSMA would result in systematically biased EC fluxes. In the following, we quantify to what extent the spectral properties of the WSMA contaminate the measured fluxes, and we correct the resulting bias. For this purpose, cospectra of the fluxes of momentum,
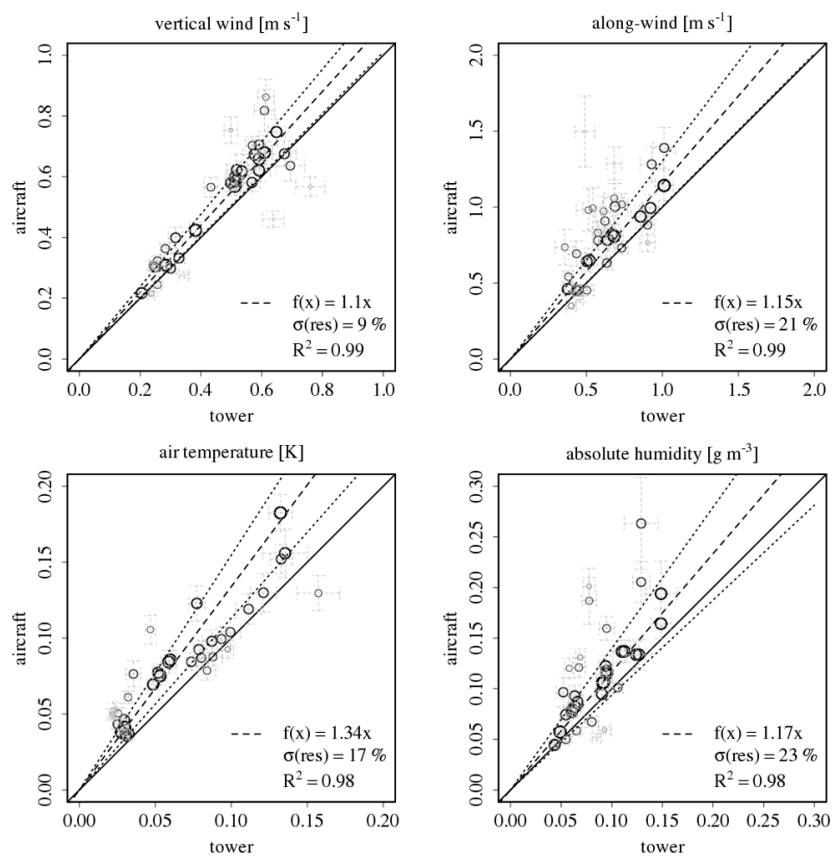

Fig. 4. Comparison between tower and WSMA standard deviations. The results are displayed in the same way as Fig. 2. Additional information is given in the text.

sensible heat and latent heat were calculated in analogy to the power spectra in Sect. 3.3.3. In Fig. 5, ensemble cospectra are presented as function of the normalized frequency $n=f \cdot z / \bar{U}$, with $\bar{U}$ being the horizontal wind speed for the tower and the true airspeed for the WSMA, respectively. This facilitates the summarization of measurements at different heights above ground and the comparison between different platforms (Desjardins et al., 1989). Also shown is the reference cospectrum of Massman and Clement (2004), with the spectral maximum at $n=0.1$ for unstable stratification (Kaimal and Finnigan, 1994; 24 out of 36 flights). The cospectra approximately follow the reference cospectrum, with exception of the momentum flux at the tower (not shown). The latter exhibits large scatter in the individual cospectra at both installation heights, which was not reduced by increasing the length of the dataset up to $30 \mathrm{~min}$. Consequently, no ensemble cospectrum was calculated for the momentum flux at the tower. For the heat fluxes, the peak of the tower cospectra coincide with $n=0.1$ of the reference cospectrum. The cospectral peaks of the WSMA measurements are marginally shifted towards higher frequencies around $n=0.2$. A slight bimodality is attributable to combining measurements under slightly varying stratification, and is not present in the cospectra of single flights (peaking between $0.05<n<0.25$ ). Nevertheless, the shape of the reference cospectrum is generally better resembled by the WSMA measurements. In Sect. 3.3.3, we related increased variance in the WSMA wind components to spectral artifacts originating from the wing. In order to quantify the impact on 

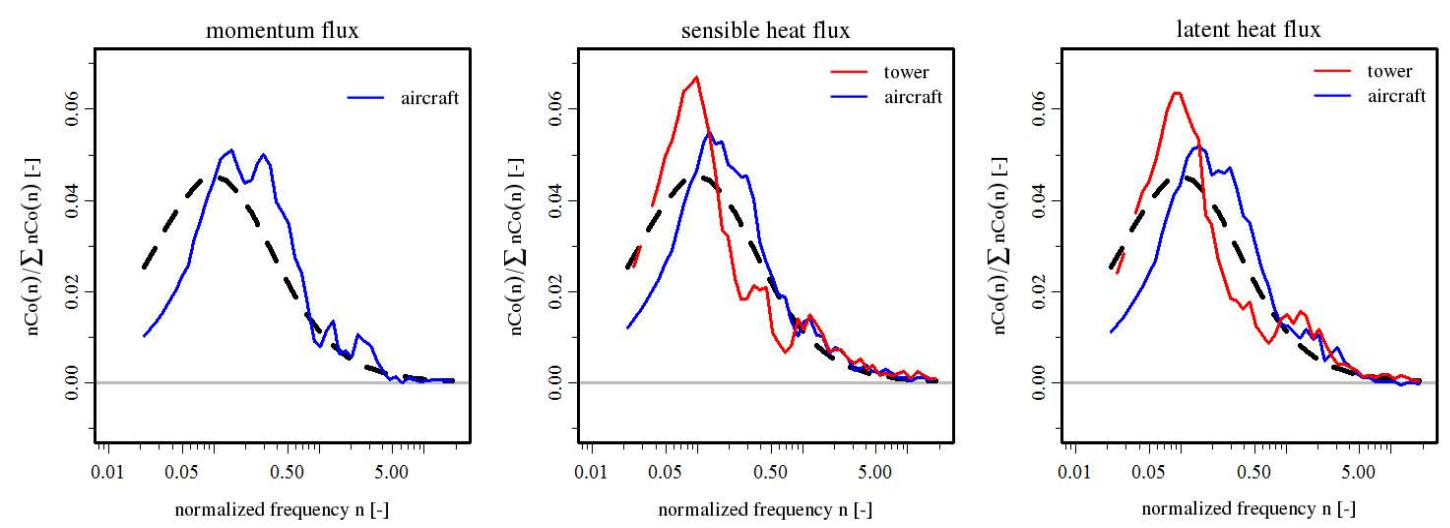

Fig. 5. Average cospectra of all measurements between tower and WSMA. Also shown is the reference cospectrum of Massman and Clement (2004, dashed line). Additional information is given in the text.

the WSMA flux measurement, all individual cospectra are compared between the WSMA and the reference cospectrum in the frequency range $f=0.4-2 \mathrm{~Hz}$ of the spectral artifacts. To account for the influence of stratification, the peaks of the reference cospectra were calculated using the forms of Kaimal et al. (1972). Relative to the entire frequency range, the spectral artifacts lead to a systematic deviation in the fluxes of momentum, sensible- and latent heat of $3 \pm 6 \%$, $-1 \pm 6 \%$ and $1 \pm 3 \%$ (median differences), respectively. Similarly, the inadequate frequency response of the tower sonic temperature measurements results in an underestimation of the sensible heat flux of $-3 \pm 5 \%$ for frequencies $>0.3 \mathrm{~Hz}$.

The covariances of the individual measurements were corrected for spectral artifacts before continuing the comparison. Finally, fluxes of momentum, sensible and latent heat are compared between EC measurements from tower and WSMA using the maximum likelihood functional relationship (Fig. 6). The WSMA estimates are 17-21\% higher compared to the tower, and the $99.5 \%$ confidence intervals enclose unity slope. Alike the SDs, the ensemble random errors of the heat fluxes are less than or equal to the slope errors (Table 2). This indicates a sufficient sample size supporting the MLFR results. The explained variance is high $(\geq 96 \%)$ for all observed fluxes. All residual standard errors are $\leq 25 \%$, and significantly lower than the respective average random statistical error (Table 2).

Our analysis revealed that differences in the measurements between tower and weight-shift microlight aircraft partially originate from spectral artifacts. After factoring in these effects, the SDs at the WSMA differ from the tower by $2-15 \%$ for the wind components, $34 \%$ for temperature and $17 \%$ for the humidity measurement. Likewise, the EC fluxes from WSMA remain in excess of $17-21 \%$ compared to the tower.

\subsection{Spatial analysis}

In the following, we investigate whether the remaining differences between WSMA and tower measurements can be related to their spatial representativeness. For this purpose, we use a cross-wind distributed footprint parameterization (Appendix B) together with the Corine 2006 Land Cover raster. The contributions from all raster cells are cumulated with distance from the measurements, resulting in footprint effect level rings (Fig. 7). When considering the average footprint contributions over all tower-WSMA comparison measurements, the spatial context of the platforms appears to agree quite well. For both platforms, most of the footprint covers arable land (95-97\%). Contributions from the remaining land covers are sub-percent except for forest (2$3 \%$ ), and meadows do not contribute at all.

Taking a closer look at the individual, simultaneous measurements, the source areas can however differ considerably (Fig. 7). The degree of overlap is less related to flight altitude than to flight direction. The footprints often agree better for flights in along-wind direction (Fig. 7a, c). Yet this is not a general rule, because the flight paths are horizontally displaced from the tower (Fig. 7b). For flights in cross-wind direction, the footprint fans out, which additionally reduces the overlap (Fig. 7d). Over all measurements, the overlap ranges from $12-68 \%$ of the footprint weights, with a median of $35 \pm 17 \%$. However, varying overlap did not systematically alter the differences in the flux measurements between tower and WSMA $\left(R^{2} \leq 0.07\right)$.

\subsection{Comparison with large-aperture scintillometer}

In order to assess principal differences of spatial averaging (large-aperture scintillometer, weight-shift microlight aircraft) and temporal averaging (tower eddy covariance), we intercompare simultaneous measurements of the sensible heat flux. In Fig. 8 (abscissa), the fluxes from all platforms are normalized by the reference sensible heat flux derived 

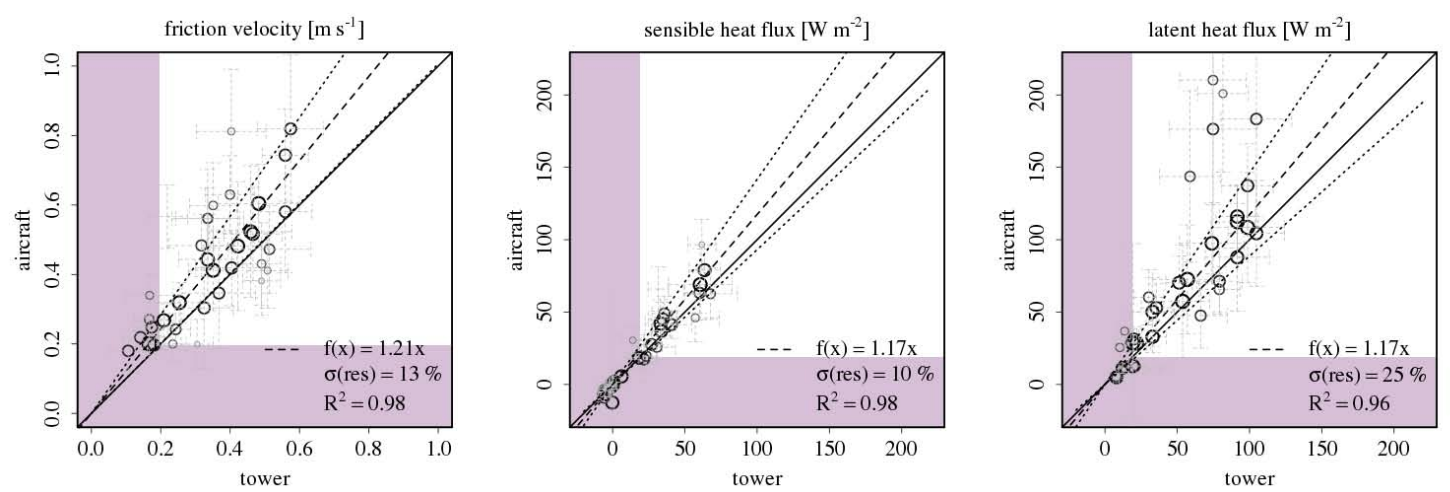

Fig. 6. Comparison between tower and WSMA eddy-covariance fluxes: friction velocity, sensible heat and latent heat. The results are displayed in the same way as Fig. 2. The data points in the shaded areas close to zero are omitted in the calculation of the normalized random errors (see Appendix A). Additional information is given in the text.

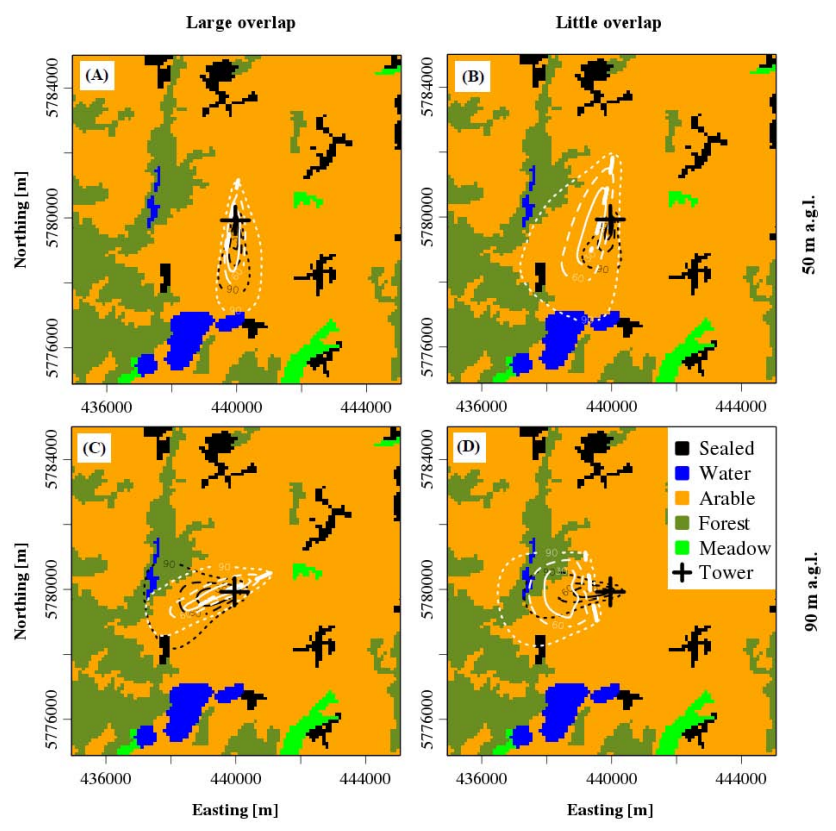

Fig. 7. Footprint effect levels of four simultaneous tower and WSMA measurements against the background of the Corine Land Cover raster $(10 \times 10 \mathrm{~km})$. The flight path (white dashed line) and the footprint effect levels are shown. Solid, dashed and dotted lines represent a cumulative footprint of $30 \%, 60 \%$ and $90 \%$, respectively. Flights (A) and (B) on 15 October 2008, 14:51-14:52 UTC and 14:09-14:12 UTC at $50 \mathrm{~m}$ a.g.l. Flights (C) and (D) on 16 October 2008, 11:36-11:38 UTC and 11:09-11:10 UTC at $90 \mathrm{~m}$ a.g.l.

from the LAS, $55 \mathrm{~W} \mathrm{~m}^{-2}$ and $45 \mathrm{~W} \mathrm{~m}^{-2}$ on 20 and $21 \mathrm{Oc}$ tober 2008, respectively. Similarly, the measuring heights (Fig. 8, ordinate) are normalized by the boundary layer depth, $450 \mathrm{~m}$ and $600 \mathrm{~m}$ on 20 and 21 October 2008, respectively. Under conditions of forced convection, $H$ can be assumed to diminish below the entrainment zone around $0.8 \mathrm{ABL}$ depth (Deardorff, 1974; Sorbjan, 2006). This allows us to approximate the vertical gradient of $H$, for which the measurements of LAS and $2.4 \mathrm{~m}$ EC are used as surface flux reference. The tower measurements at $50 \mathrm{~m}$ and $90 \mathrm{~m}$ approximately follow the vertical flux gradient derived from the EC surface flux measurements. However, it is evident that any $H$ measured by tower EC and extrapolated to flight altitude is lower by 25-40\% compared to the LAS. At the same time, $H$ measured by the WSMA is $\leq 25 \%$ lower compared to the LAS, but $15-25 \%$ higher compared to the tower measurements.

Differing source areas of the measurements (Fig. 9) qualify as a potential reason for the observed differences in the sensible heat flux. In absence of a better estimate, the LAS footprint was derived from the turbulence statistics at the $50 \mathrm{~m}$ tower EC measurement, and weighted along the LAS path (Meijninger et al., 2002; Wang et al., 1978). While southerlies prevailed on 20 October 2008 (Fig. 9a), southwesterly winds were observed on 21 October 2008 (Fig. 9b). Despite weaker winds on 20 October 2008, the footprint extent of the tower measurements is longer compared to 21 October 2008. This can be explained by different surface roughness upwind of the measurements and corresponding differences in the mechanical generation of turbulence $\left(0.2<u_{*}<0.5\right)$. The roughness lengths are $\approx 10^{-4} \mathrm{~m}$ (water upwind) and $\approx 10^{-2} \mathrm{~m}$ (forest upwind) on 20 and 21 October 2008 , respectively.

The overlap of the source areas of the tower and WSMA measurements with the LAS measurement was $<10 \%$ on 20 October 2008. On 21 October 2008, however, the overlap of WSMA and LAS increased to $37 \%$, while remaining $<10 \%$ between tower and LAS measurements. Despite the increasing overlap, WSMA and LAS fluxes did not agree as well as on the previous day. The footprints of all measurements were dominated by contributions from arable land, which generally were $>90 \%$. Only the $90 \mathrm{~m}$ tower EC measurement on 20 October 2008 had significant contributions from water bodies (13\%) and forest $(6 \%)$. Nevertheless, this measurement encloses the tower vertical flux gradient well within its random error (Fig. 8). 


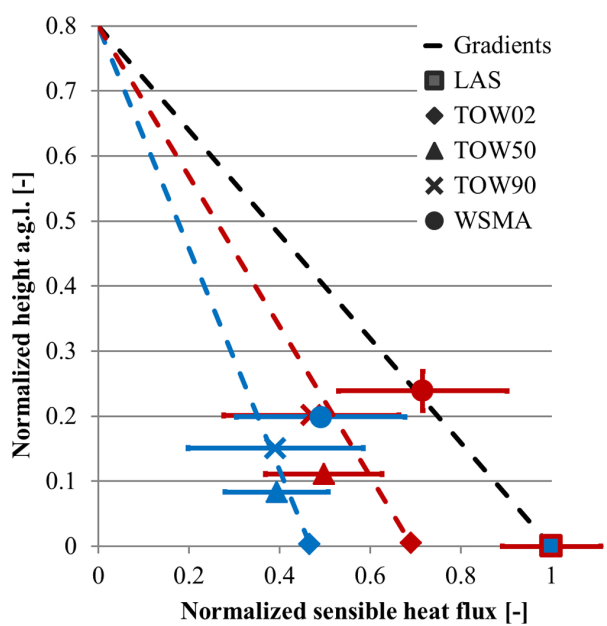

Fig. 8. Vertical profile of the sensible heat flux during two flights: 20 October 2008, 10:53-10:55 UTC (red) and 21 October 2008, 09:56-09:59 UTC (blue). Heat fluxes are compared between largeaperture scintillometer (LAS), tower eddy covariance at $2.4 \mathrm{~m}, 50 \mathrm{~m}$ and $90 \mathrm{~m}$ (TOW02, TOW50, TOW90) and the weight-shift microlight aircraft (WSMA). Where available, error bars show the random statistical error and the altitude standard deviation. Additional information is given in the text.

\section{Discussion}

The propagation of sensor errors enables defining the minimum change in an atmospheric quantity that can be reliably resolved by the WSMA measurements of respective variables. For the wind measurement, this coincides with the lower margin of the standard deviations observed at both tower and WSMA (Fig. 4). We thus conclude that the precision of the wind measurement warrants eddy-covariance flux measurements under unstable to slightly stable stratifications. The precision of the vertical wind is better by a factor of two compared to the horizontal wind components. This can be traced back to the better precision of the attack- and pitch $\left(\leq 0.08^{\circ}\right)$ angles compared to the sideslip- and heading $\left(\leq 0.18^{\circ}\right)$ angles. From the assessment of sensor accuracies, we found that the wind and scalar measurements facilitate the signal levels required for the resolution of mesoscale ABL structures. This enables extending averaging intervals and spectral analyses up to a scale of tens of kilometres.

The focus of this study is on the comparison of turbulence statistics between weight-shift microlight aircraft and tower measurements. A potential source of uncertainty is the flow distortion correction of the USA-1 sonic anemometers used at the tall tower. Two different corrections are provided by the manufacturer, of which the "milder" 2-D version was used in the operational setup of the DWD. A post processing comparison for the presented tower data shows that the 3-D version would lead to a systematic increase in the wind SDs by $\approx 35 \%$, and in the fluxes by $\approx 15 \%$. From instrument comparison, the 2-D correction seems to be more
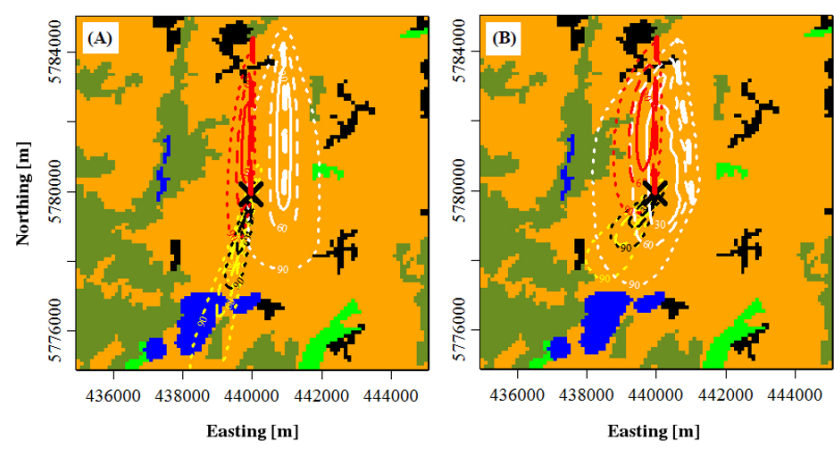

Fig. 9. Footprint effect levels of the measurements from Fig. 8 on 20 October 2008 (A) and 21 October 2008 (B), presented similarly to Fig. 7. In addition, the weighted footprint along the LAS path is shown (red), and the footprints from the tower measurements at $50 \mathrm{~m}$ (black) and $90 \mathrm{~m}$ (yellow) are distinguished.

appropriate. However, it must be noted that the magnitude of this correction alone is in the order of the differences in the wind SDs and the fluxes observed between the tower and the WSMA. Longer averaging intervals at the tower or detrending of the WSMA data did not change the general behaviour, but increased the scatter in the comparison. Moreover, vertical flux divergence can be ruled out as potential error source, since the measurements were conducted at approximately the same altitude above ground. Also, altitude fluctuations by the WSMA were accounted for by using potential quantities of temperature and densities at the tower pressure level. In the following, we consequently focus on the effects of spectral artifacts and surface heterogeneity.

During the investigation of the WSMA spectral properties, a scale discrepancy was detected between accelerations acting at the five-hole probe and their accounting in the global positioning system/inertial measurement unit, i.e. the wind computation (Fig. 1). No remnants of this scale discrepancy are evident in the wind measurements, in particular between $1-5 \mathrm{~Hz}$. This leads to the conclusions that (i) the wind vector computation correctly accounts for the displacement of 5HP and GPS/IMU, and (ii) the cause of enhanced 5HP acceleration measurements (especially longitudinal to the body) lies in the fixture of the acceleration sensor in the 5HP, rather than in the mounting of the 5HP against the GPS/IMU. The spectral peak in the WSMA vertical and streamwise wind components (Fig. 3) coincides with the wing's natural frequency around $0.7 \mathrm{~Hz}$ (Sect. 3.2). A less pronounced peak between $0.15-0.4 \mathrm{~Hz}$ in the transverse wind component coincides only with a peak in vertical accelerations (Fig. 1). Both spectral features can potentially be associated with the treatment of wing upwash in the time domain, but not in the frequency domain (Metzger et al., 2011). The WSMA wind and flux measurements were corrected for this spectral inconsistency before comparing them to ground-based measurements. The appropriate correction factors were estimated 
from the comparison of measured spectra and cospectra to modelled ones.

Because of large scatter in the momentum flux cospectra at the tower, no ensemble was calculated. We speculate that the scatter originates from the wind direction-dependent correlation of the horizontal and vertical wind components at the USA-1 sonic anemometers (e.g. Mauder et al., 2007b). The erroneous sonic temperature spectrum indicates problems with the measurement of the temperature SD and the sensible heat flux at the tower. The amplitude resolution test by Vickers and Mahrt (1997) would reject 28 out of 36 tower sonic temperature data sets. The problem was related to the insufficient sonic temperature resolution $(0.01 \mathrm{~K})$ of the USA-1, which appears as superficial spectral energy in the form of high-frequency white noise. Spectral correction factors analogous to the WSMA measurements were used in an attempt to correct the systematic overestimation of the temperature SD. Such a procedure changes the maximum likelihood functional relationship between tower and aircraft temperature SD from $-9 \%$ underestimation to $34 \%$ overestimation of the WSMA measurement. At the same time, the residual standard error in the MLFR increases from $9 \%$ to $17 \%$. The scattering can be suppressed by rejecting data points with weak temperature SD $(<0.05 \mathrm{~K})$, resulting in a reduced overestimation of $15 \%$ of the WSMA measurement. Consequently, the USA-1 measurements cannot be regarded as reliable reference for the temperature SD, and the spectral correction factors must be interpreted with caution. The problem is less pronounced for the sensible heat flux. The white noise in the USA-1 sonic temperature measurement does not affect the measurement of, or the correlation with, the vertical wind measurement. The result is a modest underestimation of $-3 \%$ of the tower sensible heat flux due to reduced coherence of sonic temperature and vertical wind at high frequencies. The humidity measurements agree well between the platforms in the time and in the frequency domain. Several outliers in the WSMA latent heat flux measurement coincide with WSMA flights west of the tall tower, which are closer to a forest edge. Increased mechanical turbulence downwind of the forest edge is a potential explanation for increased turbulent fluxes. This finding however does not hold for the sensible heat flux and the friction velocity, which is in contradiction to scalar similarity.

As a potential source for the observed differences, we assess the spatial context of the tower and aircraft measurements. The footprint results illustrate that the land cover contributions are very similar for both platforms. Provided the land cover data are a suitable proxy for the land-atmosphere exchange, differences between tower and WSMA measurements cannot be attributed to different land cover contributions alone. However, the footprint analysis also reveals that the source areas only share a fractional overlap. Consequently, the observed differences can potentially originate from the platforms' principally different sampling strategies. Foken (2008) and Mahrt (2010) conclude that the energy balance non-closure frequently observed from tower EC measurements is connected to the interaction of terrain heterogeneity and turbulent scales. For this purpose, the transfer of heat between surface and atmosphere is considered separately for smaller, random eddies and for larger, nonpropagating eddies. Thereof, the transfer by the small, random eddies is measured by the tower EC. However, an additional transfer component is suspected to occur at significant surface heterogeneities, leading to the generation of non-uniformly distributed NPEs. Based on intensive measurement campaigns and modelling efforts, the presence of NPEs in the study area has been shown (Uhlenbrock et al., 2004). At $100 \mathrm{~m}$ measuring height, the resulting average horizontal imbalance of the sensible heat flux is in the order of 4-19\% (Steinfeld et al., 2007). In the same study area, Beyrich et al. (2006) found comparable differences between surface flux estimates from aircraft and tower of $11 \%$ for the sensible heat and $23 \%$ for the latent heat. Furthermore, a tendency was shown to close the energy balance on the regional scale with spatially averaging methods (Mauder et al., 2007a). This suggests that the tower EC cannot adequately capture all flux contributions due to its inability of spatial sampling. On the other hand, a large-aperture scintillometer captures NPEs up to the dimension of its path length, with increasing sensitivity towards the centre of the path (Foken et al., 2010). Also airborne EC is capable of spatial sampling and captures some of the associated flux, depending on the horizontal extent of the NPEs and the flight path. Therefore, the presence of NPEs in the study area can be considered a potential explanation for the deviation of the tower EC results from the WSMA, and even more so from the LAS results. In order to further adjust results from tower and airborne EC measurements, the raw data could be high-pass filtered, which restricts low-frequency flux contribution to an identical threshold (e.g. Thomas et al., 2012).

This study combines several principles and methods for the purpose of quantifying: (i) the suitability of airborne instrumentation for EC measurements, (ii) the complex feedback of WSMA motions on the EC measurement, and (iii) the direct intercomparison of measurement platforms with differing spatial representativeness. The applied techniques are not restricted to use with the WSMA, but are general enough to be used for the development and assessment of other airborne platforms.

\section{Conclusions}

We have shown that turbulence measurements from a weight-shift microlight aircraft can be achieved with sufficient precision to enable eddy-covariance flux calculation. Furthermore, a coordinated setup of tall tower, large-aperture scintillometer and weight-shift microlight aircraft measurements avoids typical errors due to averaging intervals and vertical flux divergence (e.g. Betts et al., 1990). Differences 
on the order of $15-25 \%$ remain between the fluxes measured by the ground-based instruments and the WSMA. At that, the LAS generally measured the highest flux magnitude, followed by the WSMA and the tower. However, the $99.5 \%$ confidence intervals of the maximum likelihood functional relationships between tower and WSMA include unity slope. Consequently, the observed differences can be considered insignificant, and the accuracy of the WSMA flux measurement is quantified to $\leq 10 \%$ ( $1 \sigma$ slope error).

Nevertheless, several potential reasons for the disagreement of the results between the measurement platforms are investigated. (i) The WSMA wind and flux measurement is subject to spectral artifacts originating from its wing, and the results are corrected prior to the comparison. (ii) The flow distortion correction and the temperature resolution at the tower sonic anemometer measurement alone can explain the full magnitude of the disagreement. (iii) A footprint analysis allows excluding differences in the surface areas as the primary reason for the disagreement. (iv) Principal differences between spatially and temporally averaging flux measurements may also explain the observed differences. In particular, energy transfer by non-propagating eddies above heterogeneous terrain is discussed as a potential reason.

We conclude that the WSMA is a suitable tool to promote the on-going research of surface-atmosphere interactions in heterogeneous landscapes. The flux measurement is sufficiently accurate to cover the required flight transect length $(10-100 \mathrm{~km})$. Moreover, the WSMA's low ratio of true airspeed to climb rate is well suited for terrain-following flight over complex terrain. Using e.g. wavelet analysis, the regional turbulent exchange measured from the aircraft can be located in space and in spectral scale (Mauder et al., 2007a; Strunin and Hiyama, 2004). All of the above features are beneficial for the study of yet poorly understood exchange mechanisms between the Earth's surface and the atmosphere. This further substantiates the versatility of the WSMA as a low cost and widely applicable environmental research aircraft.

\section{Appendix A}

\section{Integral length scales and statistical error}

The integral length scale $\lambda$ can be interpreted as the typical size of the most energy-transporting eddies. It is calculated by integration of the autocorrelation function from zero lag to the first crossing with zero at lag $r_{0}$ (Bange et al., 2002; Lenschow and Stankov, 1986):

$\lambda=\int_{0}^{r_{0}} \frac{\left\langle f^{\prime}(x) f^{\prime}(x+r)\right\rangle}{\left\langle f^{\prime}(x)^{2}\right\rangle} \mathrm{d} r$.

Here $f$ represents a turbulent quantity $c$ (scalars or wind components), but also combinations of these with the vertical wind $f(x)=w^{\prime}(x) \cdot c^{\prime}(x)$ (Bange, 2007). Hence, the integral scales of the turbulent fluxes were directly calculated from the data of the weight-shift microlight aircraft. The transformation into the integral time scale $\tau$ of simultaneous tower measurements is carried out by division of $\lambda$ with the mean horizontal wind speed at the tower. This assumes that Taylor's hypothesis of frozen turbulence is valid (Taylor, 1915). The random statistical error of the sample average $\bar{f}$ is simply the square root of its variance $\sqrt{\overline{\left(f^{\prime}\right)^{2}}}$. However, the errors in the variance $V$ of $f$, or the covariance $F$ of its combinations, are functions of the integral scales $\lambda, \tau$. The random statistical errors $\sigma_{V}$ and $\sigma_{F}$ were determined after Lenschow and Stankov (1986); Lenschow et al. (1994):

$$
\begin{aligned}
& \sigma_{V}^{2}=2 \cdot V^{2} \cdot \frac{\lambda}{L}, \\
& \sigma_{F}^{2}=2 \cdot F^{2} \cdot \frac{\lambda}{L} \cdot \frac{1+r_{w c}^{2}}{r_{w c}^{2}},
\end{aligned}
$$

with the averaging length $L$ and the correlation coefficient between vertical wind and the turbulent quantity $r_{w c}$. It is assumed that $\lambda \ll L$, and that $w$ and $c$ are Gaussian distributed. The momentum flux consists of two orthogonal components, $\overline{u^{\prime} w^{\prime}}$ and $\overline{v^{\prime} w^{\prime}}$, with the wind components $u, v$ and $w$. The calculation of its random error is obtained from Gaussian error reproduction of the errors in its components (Bange et al., 2002). The individual random errors of the WSMA and the tower measurement, $\sigma_{\text {air }}$ and $\sigma_{\text {tow }}$, respectively, were summarized for each variable over all flight legs:

$\sigma_{\text {ran }}=\frac{\sum_{\text {air }}^{n} \sigma_{\text {air }}+\sum_{\text {tow }}^{n} \sigma_{\text {tow }}}{2 n-1}$,

resulting in the average random error in the data couples $\sigma_{\text {ran }}$ with the sample size $n$. The ensemble random error $\sigma_{\text {ens }}$ considers the reduction of the random error with the sample size (Mahrt, 1998):

$\sigma_{\mathrm{ens}}=\frac{\sigma_{\mathrm{ran}}}{\sqrt{n}}$,

with zero expected value $\sigma_{\text {ens }}$ and the standard deviation $\sigma_{\text {ran }}$ of the population. While $\sigma_{\text {ran }}$ is a measure for the average dispersion of the data couples, $\sigma_{\text {ens }}$ quantifies the level of confidence we can expect from comparing the entire dataset between the two platforms. To use Eqs. (A4)-(A5) for data obtained during different flight days, we use normalized error estimates. Yet, the normalized errors are excessively large when the denominator, i.e. the measurement quantity, approaches zero. For turbulent fluxes, this is usually the case under stable conditions, where e.g. intermittent turbulence can violate the assumptions in the integral length scales. Consequently, we constrain the calculation of $\sigma_{\text {ran }}$ and $\sigma_{\text {ens }}$ for the fluxes to values of $u_{*}>0.2 \mathrm{~m} \mathrm{~s}^{-1}$ and $H, E>20 \mathrm{~W} \mathrm{~m}^{-2}$, resulting in $N=28,15$ and 24 samples, respectively. 

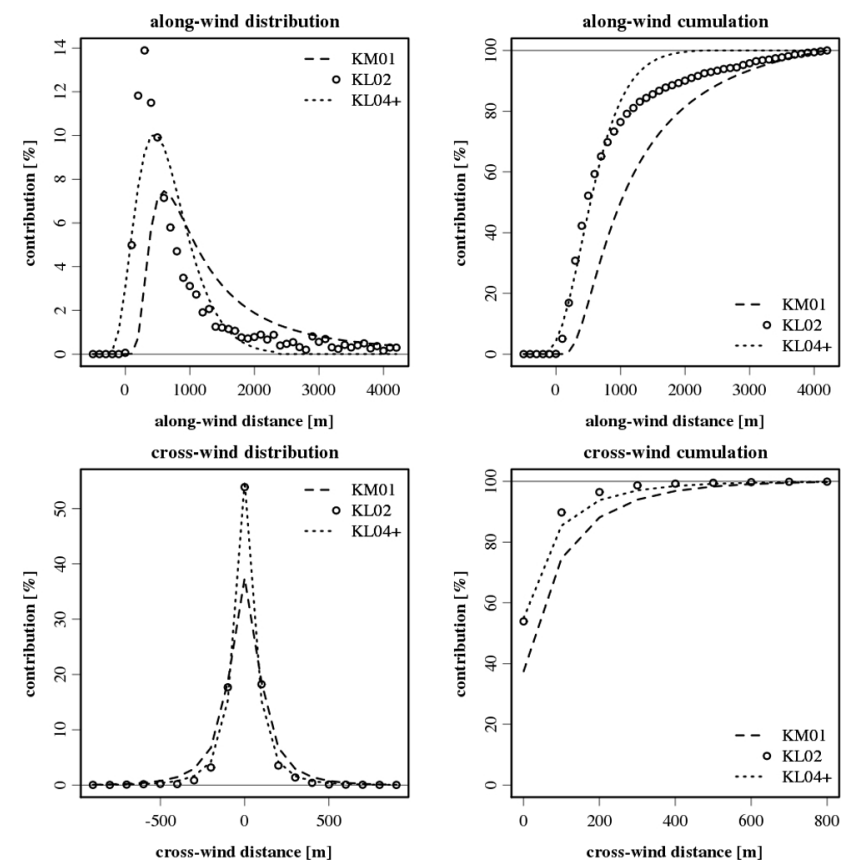

Fig. B1. Cross-wind and along-wind integrated distributions of the footprints for case 2, $z=100 \mathrm{~m}$ from Markkanen et al. (2009). Upper and lower panels display longitudinal and cross-sections, respectively. The footprint weight distributions are shown on the left side, and the cumulative distributions are shown on the right side.

\section{Appendix B}

\section{Footprint modelling}

The footprint- or source weight function quantifies the spatial contributions to each measurement (Schmid, 2002; Vesala et al., 2008). Analytical footprint models are often limited, e.g. regarding stability regimes or measurement heights (e.g. Kormann and Meixner, 2001, subsequently referred to with KM01). Lagrangian footprint models overcome these limitations and additionally consider 3-D dispersion, but are computationally expensive. The footprint model of Kljun et al. (2004, KL04) is a parameterization of the backward Lagrangian model of Kljun et al. (2002, KL02) in the range $-200 \leq z / L \leq 1, u_{*} \geq 0.2 \mathrm{~m} \mathrm{~s}^{-1}$, and $1 \mathrm{~m} \leq z \leq z_{i}$, with the boundary layer depth $z_{i}$. Thus, it combines little computational effort with broad applicability. The parameterization depends upon friction velocity $u_{*}$, measurement height $z$, standard deviation of the vertical wind $\sigma_{w}$ and the aerodynamic roughness length $z_{0}$, of which $u_{*}, z$ and $\sigma_{w}$ are measured directly. The roughness length is inferred using the logarithmic wind profile with the integrated universal function for momentum exchange after Businger et al. (1971) in the form of Högström (1988). The KL04 is a cross-wind integrated footprint model, i.e. it does not resolve the distribution perpendicular to the main wind direction. In order to account for cross-wind dispersion, the KL04 was combined with
Table B1. Median performance of the footprint parameterizations KL04+ and KM01 compared to the reference Lagrangian model of Kljun et al. (2002). Uncertainty measures NMSE, MAD and $r$ are explained in the text.

\begin{tabular}{|c|c|c|c|c|}
\hline \multirow{2}{*}{$\begin{array}{l}\text { Direction } \\
\text { Model }\end{array}$} & \multicolumn{2}{|c|}{ Along-wind } & \multicolumn{2}{|c|}{ Cross-wind } \\
\hline & KL04+ & KM01 & KL04+ & KM01 \\
\hline NMSE & $0.34 \pm 0.05$ & $0.95 \pm 0.48$ & $0.34 \pm 0.05$ & $0.33 \pm 0.36$ \\
\hline MAD [\%] & $0.43 \pm 0.10$ & $0.63 \pm 0.28$ & $0.08 \pm 0.05$ & $0.12 \pm 0.14$ \\
\hline$r$ & $0.91 \pm 0.00$ & $0.66 \pm 0.12$ & $0.99 \pm 0.01$ & $0.99 \pm 0.01$ \\
\hline
\end{tabular}

a Gaussian cross-wind distribution function (Kljun et al., 2012). The combination of KL04 with this cross-wind distribution results in a computationally fast footprint parameterization which considers 3-D dispersion and is not constrained to applications in the surface layer. In the following, we refer to this model as KL04+.

To evaluate model performance, KM01 and KL04+ were compared to the reference Lagrangian model KL02. For this purpose, four existing realizations of the KL02 model were used from Markkanen et al. (2009, Table 1, case 1 ( $L=$ $\left.-32 \mathrm{~m}, u_{*}=0.27 \mathrm{~m} \mathrm{~s}^{-1}\right)$ and case $2\left(L=-76.6 \mathrm{~m}, u_{*}=\right.$ $\left.0.295 \mathrm{~m} \mathrm{~s}^{-1}\right), z=50 \mathrm{~m}$ and $100 \mathrm{~m}$ ). Markkanen et al. (2009) adopted case 1 from Leclerc et al. (1997), and referenced the results to large eddy simulations (Raasch and Schröter, 2001). The above parameter sets do not include $\sigma_{v}$ and $\sigma_{w}$, which were derived using the integral turbulence characteristics proposed by Lumley and Panofsky (1964) and Panofsky et al. (1977), respectively. The computed footprint weights were summarized for each cell of a grid with $100 \mathrm{~m}$ horizontal spacing and subsequently integrated over cross-wind and along-wind direction, respectively (Fig. B1). In both directions, KL04+ assigns more weight to the close range compared to KM01 (Fig. B1 left panels). This is consistent throughout the range of the tested atmospheric conditions (not shown). In along-wind direction, KL04+ reproduces KL02 very well until the cumulative distribution accounts for approximately $80 \%$ of the footprint (Fig. B1 upper right panel). Contributions from below the measurement location due to along-wind dispersion are slightly pronounced by KL04+, and neglected by KM01. The cross-wind distributions of both KL04+ and KM01 agree reasonably well with KL02.

To quantify the model comparison, normalized mean square error (NMSE, Hanna and Paine, 1989), median absolute deviation (MAD, Rousseeuw and Verboven, 2002) and Pearson's coefficient of correlation $(r)$ are used. The NMSE is based on variance statistics and is thus sensitive to the few largest deviations in the dataset. In contrast, the MAD is the middle value of the error distribution, and is more sensitive to the error frequency. We use NMSE and MAD to assess the model performance around the peak and the tail of the footprint, respectively. The correlation coefficient provides information on the degree of similarity between the models' distributions. Table B1 summarizes the results of the model 
comparison. In both along-wind and cross-wind directions, the similarity between KL04+ and KL02 is as good or better than between KM01 and KL02 $(r)$. In along-wind direction, KL04+ is considerably closer to KL02 in the close range (NMSE) and the far range (MAD) compared to KM01. A similar deviation between KM01 and KL02 has been reported by Kljun et al. (2003). In cross-wind direction, both KL04+ and KM01 agree equally well with KL02. For all metrics, the standard errors over the four parameter sets are smaller for the KL04+ model, pointing out its reliability.

Acknowledgements. Recognition has to be given to Frank Neidl and Rainer Steinbrecher at the Karlsruhe Institute of Technology, Institute for Meteorology and Climate Research. Neidl programmed and continuously maintained the data acquisition system, while Steinbrecher initiated wind- and flux measurements with the weight-shift microlight aircraft in the first place. Thanks go to Ulrich Weisensee and Jens-Peter Leps at the German Meteorological Service, Richard-Aßmann-Observatory Lindenberg for performing the tower turbulence measurements. We are obliged to Xunhua Zheng and her workgroup at the Chinese Academy of Sciences, Institute of Atmospheric Physics, which was hosting our project and providing indispensable infrastructure. Our thanks to Jens Bange at the Eberhard Karls University of Tübingen, Institute for Geoscience, for his advice regarding the flight campaign design. The authors wish to thank Henry Loescher at the National Ecological Observatory Network, Fundamental Instrument Unit for his continued support. Stipend funding by the German Academic Exchange Service, Helmholtz Association of German Research Centres, China Scholarship Council and the European Union under the Science and Technology Fellowship China is acknowledged. The National Ecological Observatory Network is a project sponsored by the National Science Foundation and managed under cooperative agreement by NEON, Inc. This material is based upon work supported by the National Science Foundation under the grant DBI-0752017. Any opinions, findings, and conclusions or recommendations expressed in this material are those of the authors and do not necessarily reflect the views of the National Science Foundation.

Edited by: S. Malinowski

\section{References}

Bange, J.: Airborne Measurement of Turbulent Energy Exchange Between the Earth Surface and the Atmosphere, Faculty of Engineering, Braunschweig University of Technology, Braunschweig, Germany, 2007.

Bange, J., Beyrich, F., and Engelbart, D. A. M.: Airborne measurements of turbulent fluxes during LITFASS-98: Comparison with ground measurements and remote sensing in a case study, Theor. Appl. Climatol., 73, 35-51, doi:10.1007/s00704002-0692-6, 2002.

Betts, A. K., Desjardins, R. L., Macpherson, J. I., and Kelly, R. D.: Boundary-layer heat and moisture budgets from FIFE, Bound.Lay. Meteorol., 50, 109-138, doi:10.1007/BF00120520, 1990.
Beyrich, F. and Adam, W. K.: Site and data report for the Lindenberg reference site in CEOP - phase I, Berichte des Deutschen Wetterdienstes, 55 pp., 2007.

Beyrich, F., Leps, J. P., Mauder, M., Bange, J., Foken, T., Huneke, S., Lohse, H., Ludi, A., Meijninger, W. M. L., Mironov, D., Weisensee, U., and Zittel, P.: Area-averaged surface fluxes over the LITFASS region based on eddycovariance measurements, Bound.-Lay. Meteorol., 121, 33-65, doi:10.1007/s10546-006-9052-x, 2006.

Businger, J. A., Wyngaard, J. C., Izumi, Y., and Bradley, E. F.: Flux-profile relationships in the atmospheric surface layer, J. Atmos. Sci., 28, 181-189, doi:10.1175/15200469(1971)028<0181:FPRITA>2.0.CO;2, 1971.

Chen, J., Jonsson, P., Tamura, M., Gu, Z. H., Matsushita, B., and Eklundh, L.: A simple method for reconstructing a high-quality NDVI time-series data set based on the Savitzky-Golay filter, Remote Sens. Environ., 91, 332-344, doi:10.1016/j.rse.2004.03.014, 2004.

Davis, F. W., Schimel, D. S., Friedl, M. A., Michaelsen, J. C., Kittel, T. G. F., Dubayah, R., and Dozier, J.: Covariance of biophysical data with digital topographic and land use maps over the FIFE site, J. Geophys. Res.-Atmos., 97, 19009-19021, doi:10.1029/92jd01345, 1992.

Deardorff, J. W.: Three-dimensional numerical study of turbulence in an entraining mixed layer, Bound.-Lay. Meteorol., 7, 199-226, doi:10.1007/bf00227913, 1974.

Desjardins, R. L., MacPherson, J. I., Schuepp, P. H., and Karanja, F.: An evaluation of aircraft flux measurements of $\mathrm{CO}_{2}$, water vapor and sensible heat, Bound.-Lay. Meteorol., 47, 55-69, doi:10.1007/BF00122322, 1989.

Desjardins, R. L., MacPherson, J. I., Mahrt, L., Schuepp, P., Pattey, E., Neumann, H., Baldocchi, D., Wofsy, S., Fitzjarrald, D., McCaughey, H., and Joiner, D. W.: Scaling up flux measurements for the boreal forest using aircraft-tower combinations, J. Geophys. Res.-Atmos., 102, 29125-29133, doi:10.1029/97JD00278, 1997.

Egger, J., Bajrachaya, S., Heinrich, R., Kolb, P., Lammlein, S., Mech, M., Reuder, J., Schaper, W., Shakya, P., Schween, J., and Wendt, H.: Diurnal winds in the Himalayan Kali Gandaki valley. Part III: Remotely piloted aircraft soundings, Month. Weather Rev., 130, 2042-2058, doi:10.1175/15200493(2002)130<2042:DWITHK>2.0.CO;2, 2002.

Foken, T.: The energy balance closure problem: an overview, Ecol. Appl., 18, 1351-1367, doi:10.1890/06-0922.1, 2008.

Foken, T., Göckede, M., Mauder, M., Mahrt, L., Amiro, B., and Munger, W.: Post-field Data Quality Conirol, in: Handbook of Micrometeorology: A Guide for Surface Flux Measurement and Analysis, 1st Edn., edited by: Lee, X., Law, B., and Massman, W., Springer Netherlands, Dordrecht, The Netherlands, 264 pp., 2004.

Foken, T., Mauder, M., Liebethal, C., Wimmer, F., Beyrich, F., Leps, J.-P., Raasch, S., DeBruin, H. A. R., Meijninger, W. M. L., and Bange, J.: Energy balance closure for the LITFASS2003 experiment, Theor. Appl. Climatol., 101, 149-160, doi:10.1007/s00704-009-0216-8, 2010.

Foken, T., Leuning, R., Oncley, S. P., Mauder, M., and Aubinet, M.: Corrections and data quality, in: Eddy Covariance: A Practical Guide to Measurement and Data Analysis, edited by: Aubinet, M., Vesala, T., and Papale, D., Springer, Dordrecht, Heidel- 
berg, London, New York, 85-131, 2012.

Garman, K. E., Hill, K. A., Wyss, P., Carlsen, M., Zimmerman, J. R., Stirm, B. H., Carney, T. Q., Santini, R., and Shepson, P. B.: An airborne and wind tunnel evaluation of a wind turbulence measurement system for aircraft-based flux measurements, J. Atmos. Ocean. Tech., 23, 1696-1708, doi:10.1175/JTECH1940.1, 2006. Göckede, M., Foken, T., Aubinet, M., Aurela, M., Banza, J., Bernhofer, C., Bonnefond, J. M., Brunet, Y., Carrara, A., Clement, R., Dellwik, E., Elbers, J., Eugster, W., Fuhrer, J., Granier, A., Grünwald, T., Heinesch, B., Janssens, I. A., Knohl, A., Koeble, R., Laurila, T., Longdoz, B., Manca, G., Marek, M., Markkanen, T., Mateus, J., Matteucci, G., Mauder, M., Migliavacca, M., Minerbi, S., Moncrieff, J., Montagnani, L., Moors, E., Ourcival, J.-M., Papale, D., Pereira, J., Pilegaard, K., Pita, G., Rambal, S., Rebmann, C., Rodrigues, A., Rotenberg, E., Sanz, M. J., Sedlak, P., Seufert, G., Siebicke, L., Soussana, J. F., Valentini, R., Vesala, T., Verbeeck, H., and Yakir, D.: Quality control of CarboEurope flux data - Part 1: Coupling footprint analyses with flux data quality assessment to evaluate sites in forest ecosystems, Biogeosciences, 5, 433-450, doi:10.5194/bg-5-433-2008, 2008.

Hanna, S. R. and Paine, R. J.: Hybrid Plume Dispersion Model (HPDM) development and evaluation, J. Appl. Meteorol., 28, 206-224, doi:10.1175/15200450(1989)028<0206:HPDMDA > 2.0.CO;2, 1989.

Hiyama, T., Strunin, M. A., Tanaka, H., and Ohta, T.: The development of local circulations around the Lena River and their effect on tower-observed energy imbalance, Hydrol. Process., 21, 2038-2048, doi:10.1002/hyp.6705, 2007.

Hobbs, S., Dyer, D., Courault, D., Olioso, A., Lagouarde, J. P., Kerr, Y., McAneney, J., and Bonnefond, J.: Surface layer profiles of air temperature and humidity measured from unmanned aircraft, Agronomie, 22, 635-640, doi:10.1051/agro:2002050, 2002.

Högström, U.: Non-dimensional wind and temperature profiles in the atmospheric surface layer: A re-evaluation, Bound.-Lay. Meteorol., 42, 55-78, doi:10.1007/BF00119875, 1988.

Hojstrup, J.: A statistical data screening procedure, Meas. Sci. Technol., 4, 153-157, doi:10.1088/0957-0233/4/2/003, 1993.

Isaac, P. R., Leuning, R., Hacker, J. M., Cleugh, H. A., Coppin, P. A., Denmead, O. T., and Raupach, M. R.: Estimation of regional evapotranspiration by combining aircraft and ground-based measurements, Bound.-Lay. Meteorol., 110, 6998, doi:10.1023/A:1026054317990, 2004a.

Isaac, P. R., McAneney, J., Leuning, R., and Hacker, J. M.: Comparison of aircraft and ground-based flux measurements during OASIS95, Bound.-Lay. Meteorol., 110, 39-67, doi:10.1023/A:1026002301152, 2004b.

Junkermann, W.: An ultralight aircraft as platform for research in the lower troposphere: System performance and first results from radiation transfer studies in stratiform aerosol layers and broken cloud conditions, J. Atmos. Ocean. Tech., 18, 934-946, doi:10.1175/1520-0426(2001)018<0934:AUAAPF>2.0.CO;2, 2001.

Junkermann, W.: The actinic UV-radiation budget during the ESCOMPTE campaign 2001: results of airborne measurements with the microlight research aircraft D-MIFU, Atmos. Res., 74, 461-475, doi:10.1016/j.atmosres.2004.06.009, 2005.
Kaimal, J. C. and Finnigan, J. J.: Atmospheric Boundary Layer Flows: Their Structure and Measurement, Oxford University Press, 289 pp., New York, USA, 1994.

Kaimal, J. C., Wyngaard, J. C., Izumi, Y., and Coté, O. R.: Spectral characteristics of surface-layer turbulence, Q. J. Roy. Meteorol. Soc., 98, 563-589, doi:10.1002/qj.49709841707, 1972.

Kanda, M., Inagaki, A., Letzel, M. O., Raasch, S., and Watanabe, T.: LES study of the energy imbalance problem with Eddy covariance fluxes, Bound.-Lay. Meteorol., 110, 381-404, doi:10.1023/B:BOUN.0000007225.45548.7a, 2004.

Kljun, N., Rotach, M. W., and Schmid, H. P.: A three-dimensional backward lagrangian footprint model for a wide range of boundary-layer stratifications, Bound.-Lay. Meteorol., 103, 205226, doi:10.1023/A:1014556300021, 2002.

Kljun, N., Kormann, R., Rotach, M. W., and Meixer, F. X.: Comparison of the Langrangian footprint model LPDM-B with an analytical footprint model, Bound.-Lay. Meteorol., 106, 349-355, doi:10.1023/A:1021141223386, 2003.

Kljun, N., Calanca, P., Rotach, M. W., and Schmid, H. P.: A simple parameterisation for flux footprint predictions, Bound.-Lay. Meteorol., 112, 503-523, doi:10.1023/B:BOUN.0000030653.71031.96, 2004.

Kljun, N., Rotach, M. W., and Schmid, H. P.: A Simple Parameterisation for Two-dimensional Flux Footprints, in preparation, 2012.

Kolmogorov, A. N.: Lokalnaja struktura turbulentnosti v neschtschimaemoi schidkosti pri otschen bolschich tschislach Reynoldsa (The local structure of turbulence in incompressible viscous fluid for very large Reynolds numbers), Proceedings of the USSR Academy of Sciences, 30, 299-303, 1941.

Kormann, R. and Meixner, F. X.: An analytical footprint model for non-neutral stratification, Bound.-Lay. Meteorol., 99, 207-224, doi:10.1023/A:1018991015119, 2001.

Kvalseth, T. O.: Cautionary note about $R^{2}$, Am. Stat., 39, 279-285, 1985.

Leclerc, M. Y., Shen, S., and Lamb, B.: Observations and largeeddy simulation modeling of footprints in the lower convective boundary layer, J. Geophys. Res.-Atmos., 102, 9323-9334, doi:10.1029/96JD03984, 1997.

Lenschow, D. H. and Stankov, B. B.: Length Scales in the Convective Boundary Layer, J. Atmos. Sci., 43, 1198-1209, doi:10.1175/1520-0469(1986)043<1198:LSITCB > 2.0.CO;2, 1986.

Lenschow, D. and Sun, J.: The spectral composition of fluxes and variances over land and sea out to the mesoscale, Bound.-Lay. Meteorol., 125, 63-84, doi:10.1007/s10546-007-9191-8, 2007.

Lenschow, D. H., Mann, J., and Kristensen, L.: How long is long enough when measuring fluxes and other turbulence statistics?, J. Atmos. Ocean. Tech., 11, 661-673, doi:10.1175/15200426(1994)011<0661:HLILEW> 2.0.CO;2, 1994.

Lindley, D. V.: Regression lines and the linear functional relationship, Supplement, J. R. Stat. Soc., 9, 218-244, 1947.

Liu, H. P., Peters, G., and Foken, T.: New equations for sonic temperature variance and buoyancy heat flux with an omnidirectional sonic anemometer, Bound.-Lay. Meteorol., 100, 459-468, doi:10.1023/A:1019207031397, 2001.

Liu, S. M., Xu, Z. W., Wang, W. Z., Jia, Z. Z., Zhu, M. J., Bai, J., and Wang, J. M.: A comparison of eddy-covariance and large aperture scintillometer measurements with respect to the energy bal- 
ance closure problem, Hydrol. Earth Syst. Sci., 15, 1291-1306, doi:10.5194/hess-15-1291-2011, 2011.

Lu, L., Denning, A. S., da Silva-Dias, M. A., da Silva-Dias, P., Longo, M., Freitas, S. R., and Saatchi, S.: Mesoscale circulations and atmospheric $\mathrm{CO}_{2}$ variations in the Tapajos Region, Para, Brazil, J. Geophys. Res.-Atmos., 110, 1-17, doi:10.1029/2004JD005757, 2005.

Lumley, J. L. and Panofsky, H. A.: The Structure of Atmospheric Turbulence, Interscience Publishers, New York, 1964.

Mahrt, L.: Flux sampling errors for aircraft and towers, J. Atmos. Ocean. Tech., 15, 416-429, doi:10.1175/15200426(1998)015<0416:FSEFAA>2.0.CO;2, 1998.

Mahrt, L.: Computing turbulent fluxes near the surface: needed improvements, Agr. Forest Meteorol., 150, 501-509, doi:10.1016/j.agrformet.2010.01.015, 2010.

Markkanen, T., Steinfeld, G., Kljun, N., Raasch, S., and Foken, T.: Comparison of conventional Lagrangian stochastic footprint models against LES driven footprint estimates, Atmos. Chem. Phys., 9, 5575-5586, doi:10.5194/acp-9-5575-2009, 2009.

Martin, S., Bange, J., and Beyrich, F.: Meteorological profiling of the lower troposphere using the research UAV " $\mathrm{M}^{2} \mathrm{AV}$ Carolo", Atmos. Meas. Tech., 4, 705-716, doi:10.5194/amt-4-705-2011, 2011.

Massman, W. J. and Clement, R.: Uncertainty in Eddy Covariance flux estimates resulting from spectral attenuation, in: Handbook of Micrometeorology: A Guide for Surface Flux Measurement and Analysis, 1st Edn., edited by: Lee, X., Law, B., and Massman, W., Springer Netherlands, Dordrecht, The Netherlands, 264 pp., 2004.

Mauder, M. and Foken, T.: Impact of post-field data processing on eddy covariance flux estimates and energy balance closure, Meteorol. Z., 15, 597-609, doi:10.1127/0941-2948/2006/0167, 2006.

Mauder, M. and Foken, T.: Documentation and Instruction Manual of the Eddy-Covariance Software Package TK3, Universitätsbibliothek Bayreuth, Universität Bayreuth, Abteilung Mikrometeorologie, Bayreuth, Germany, 2011.

Mauder, M., Desjardins, R. L., and MacPherson, I.: Scale analysis of airborne flux measurements over heterogeneous terrain in a boreal ecosystem, J. Geophys. Res.-Atmos., 112, D13112, doi:10.1029/2006JD008133, 2007a.

Mauder, M., Oncley, S. P., Vogt, R., Weidinger, T., Ribeiro, L., Bernhofer, C., Foken, T., Kohsiek, W., De Bruin, H. A. R., and Liu, H.: The energy balance experiment EBEX-2000. Part II: Intercomparison of eddy-covariance sensors and post-field data processing methods, Bound.-Lay. Meteorol., 123, 29-54, $2007 \mathrm{~b}$.

Meijninger, W. M. L., Hartogensis, O. K., Kohsiek, W., Hoedjes, J. C. B., Zuurbier, R. M., and De Bruin, H. A. R.: Determination of area-averaged sensible heat fluxes with a large aperture scintillometer over a heterogeneous surface Flevoland field experiment, Bound.-Lay. Meteorol., 105, 37-62, doi:10.1023/a:1019647732027, 2002.

Meijninger, W. M. L., Beyrich, F., Lüdi, A., Kohsiek, W., and De Bruin, H. A. R.: Scintillometer-based turbulent fluxes of sensible and latent heat over a heterogeneous land surface - a contribution to LITFASS-2003, Bound.-Lay. Meteorol., 121, 89-110, doi:10.1007/s10546-005-9022-8, 2006.

Metzger, S., Junkermann, W., Butterbach-Bahl, K., Schmid, H. P., and Foken, T.: Measuring the 3-D wind vector with a weightshift microlight aircraft, Atmos. Meas. Tech., 4, 1421-1444, doi:10.5194/amt-4-1421-2011, 2011.

Moore, C. J.: Frequency-response corrections for Eddycorrelation systems, Bound.-Lay. Meteorol., 37, 17-35, doi:10.1007/BF00122754, 1986.

Panofsky, H., Tennekes, H., Lenschow, D., and Wyngaard, J.: The characteristics of turbulent velocity components in the surface layer under convective conditions, Bound.-Lay. Meteorol., 11, 355-361, doi:10.1007/bf02186086, 1977.

Quenouille, M. H.: Notes on bias in estimation, Biometrika, 43, 353-360, doi:10.1093/biomet/43.3-4.353, 1956.

R Development Core Team: A Language and Environment for Statistical Computing, R Foundation for Statistical Computing, Vienna, Austria, 2011.

Raasch, S. and Schröter, M.: PALM - A large-eddy simulation model performing on massively parallel computers, Meteorol. Z., 10, 363-372, doi:10.1127/0941-2948/2001/0010-0363, 2001.

Ripley, B. D. and Thompson, M.: Regression techniques for the detection of analytical bias, Analyst, 112, 377-383, doi:10.1039/an9871200377, 1987.

Rousseeuw, P. J. and Verboven, S.: Robust estimation in very small samples, Comput. Stat. Data An., 40, 741-758, doi:10.1016/S0167-9473(02)00078-6, 2002.

Schmid, H. P.: Footprint modeling for vegetation atmosphere exchange studies: a review and perspective, Agr. Forest Meteorol., 113, 159-183, doi:10.1016/S0168-1923(02)00107-7, 2002.

Sorbjan, Z.: Statistics of scalar fields in the atmospheric boundary layer based on large-Eddy simulations. Part II: Forced convection, Bound.-Lay. Meteorol., 119, 57-79, doi:10.1007/s10546005-9014-8, 2006.

Steinfeld, G., Letzel, M. O., Raasch, S., Kanda, M., and Inagaki, A.: Spatial representativeness of single tower measurements and the imbalance problem with eddy-covariance fluxes: results of a large-eddy simulation study, Bound.-Lay. Meteorol., 123, 77-98, doi:10.1007/s10546-006-9133-x, 2007.

Strunin, M. A. and Hiyama, T.: Applying wavelet transforms to analyse aircraft-measured turbulence and turbulent fluxes in the atmospheric boundary layer over Eastern Siberia, Hydrol. Process., 18, 3081-3098, doi:10.1002/hyp.5750, 2004.

Taylor, G. I.: Eddy motion in the atmosphere, Philos. T. R. Soc. Lond., 215, 1-26, doi:10.1098/rsta.1915.0001, 1915.

Thomas, R. M., Lehmann, K., Nguyen, H., Jackson, D. L., Wolfe, D., and Ramanathan, V.: Measurement of turbulent water vapor fluxes using a lightweight unmanned aerial vehicle system, Atmos. Meas. Tech., 5, 243-257, doi:10.5194/amt-5-243-2012, 2012.

Tukey, J. W.: Bias and confidence in not-quite large samples, Ann. Math. Stat., 29, p. 614, 1958.

Uhlenbrock, J., Raasch, S., Hennemuth, B., Zittel, P., and Meijninger, W. M. L.: Effects of land surface heterogeneities on the boundary structure and turbulence during LITFASS-2003: largeeddy simulations in comparison with turbulence measurements, 16th AMS Symposium on Boundary Layers and Turbulence, Portland, USA, Abstract No. 9.3, 8-13 August, 2004.

Vesala, T., Kljun, N., Rannik, U., Rinne, J., Sogachev, A., Markkanen, T., Sabelfeld, K., Foken, T., and Leclerc, M. Y.: Flux and concentration footprint modelling: State of the art, Environ. Pollut., 152, 653-666, doi:10.1016/j.envpol.2007.06.070, 2008.

Vickers, D. and Mahrt, L.: Quality control and flux sampling problems for tower and aircraft data, J. At- 
mos. Ocean. Tech., 14, 512-526, doi:10.1175/15200426(1997)014<0512:QCAFSP>2.0.CO;2, 1997.

Wang, T. I., Ochs, G. R., and Clifford, S. F.: A saturation-resistant optical scintillometer to measure $C_{\mathrm{n}}^{2}$, J. Opt. Soc. Am., 68, 334338, doi:10.1364/JOSA.68.000334, 1978.

Webb, E. K., Pearman, G. I., and Leuning, R.: Correction of flux measurements for density effects due to heat and water vapour transfer, Q. J. Roy. Meteorol. Soc., 106, 85-100, doi:10.1002/qj.49710644707, 1980.
Wilczak, J. M., Oncley, S. P., and Stage, S. A.: Sonic anemometer tilt correction algorithms, Bound.-Lay. Meteorol., 99, 127-150, doi:10.1023/A:1018966204465, 2001.

Willett, J. B. and Singer, J. D.: Another cautionary note about $R^{2}$ : its use in weighted least-squares regression analysis, Am. Stat., 42, 236-238, 1988. 